\title{
On the formation of sulphuric acid - amine clusters in varying atmospheric conditions and its influence on atmospheric new particle formation
}

\author{
P. Paasonen ${ }^{1,2}$, T. Olenius ${ }^{1}$, O. Kupiainen ${ }^{1}$, T. Kurtén ${ }^{3}$, T. Petäjä ${ }^{1}$, W. Birmili ${ }^{4}$, A. Hamed ${ }^{5}$, M. Hu ${ }^{6}$, L. G. Huey ${ }^{7}$, \\ C. Plass-Duelmer ${ }^{8}$, J. N. Smith ${ }^{5,9}$, A. Wiedensohler ${ }^{4}$, V. Loukonen ${ }^{1}$, M. J. McGrath ${ }^{1,10}$, I. K. Ortega ${ }^{1}$, \\ A. Laaksonen ${ }^{5,11}$, H. Vehkamäki ${ }^{1}$, V.-M. Kerminen ${ }^{1}$, and M. Kulmala ${ }^{1}$ \\ ${ }^{1}$ Department of Physics, University of Helsinki, Helsinki, Finland \\ ${ }^{2}$ International Institute for Applied Systems Analysis, Laxenburg, Austria \\ ${ }^{3}$ Department of Chemistry, University of Helsinki, Helsinki, Finland \\ ${ }^{4}$ Leibniz Institute for Tropospheric Research, Leipzig, Germany \\ ${ }^{5}$ Department of Applied Physics, University of Eastern Finland, Kuopio, Finland \\ ${ }^{6}$ State Key Joint Laboratory of Environmental Simulation and Pollution Control, College of Environmental Sciences and \\ Engineering, Peking University, Beijing, China \\ ${ }^{7}$ School of Earth and Atmospheric Sciences, Georgia Institute of Technology, Atlanta, USA \\ ${ }^{8}$ Hohenpeissenberg Meteorological Observatory, German Meteorological Service, Germany \\ ${ }^{9}$ National Center for Atmospheric Research, Boulder, Colorado, USA \\ ${ }^{10}$ Department of Biophysics, Graduate School of Science, Kyoto University, Kyoto, Japan \\ ${ }^{11}$ Finnish Meteorological Institute, Helsinki, Finland
}

Correspondence to: P. Paasonen (pauli.paasonen@helsinki.fi)

Received: 26 March 2012 - Published in Atmos. Chem. Phys. Discuss.: 4 May 2012

Revised: 14 September 2012 - Accepted: 19 September 2012 - Published: 5 October 2012

\begin{abstract}
Sulphuric acid is a key component in atmospheric new particle formation. However, sulphuric acid alone does not form stable enough clusters to initiate particle formation in atmospheric conditions. Strong bases, such as amines, have been suggested to stabilize sulphuric acid clusters and thus participate in particle formation. We modelled the formation rate of clusters with two sulphuric acid and two amine molecules $\left(J_{\mathrm{A} 2 \mathrm{~B} 2}\right)$ at varying atmospherically relevant conditions with respect to concentrations of sulphuric acid $\left(\left[\mathrm{H}_{2} \mathrm{SO}_{4}\right]\right)$, dimethylamine ([DMA]) and trimethylamine ([TMA]), temperature and relative humidity (RH). We also tested how the model results change if we assume that the clusters with two sulphuric acid and two amine molecules would act as seeds for heterogeneous nucleation of organic vapours (other than amines) with higher atmospheric concentrations than sulphuric acid. The modelled formation rates $J_{\mathrm{A} 2 \mathrm{~B} 2}$ were functions of sulphuric acid concentration with close to quadratic dependence, which is in
\end{abstract}

good agreement with atmospheric observations of the connection between the particle formation rate and sulphuric acid concentration. The coefficients $K_{\mathrm{A} 2 \mathrm{~B} 2}$ connecting the cluster formation rate and sulphuric acid concentrations as $J_{\mathrm{A} 2 \mathrm{~B} 2}=K_{\mathrm{A} 2 \mathrm{~B} 2}\left[\mathrm{H}_{2} \mathrm{SO}_{4}\right]^{2}$ turned out to depend also on amine concentrations, temperature and relative humidity. We compared the modelled coefficients $K_{\mathrm{A} 2 \mathrm{~B} 2}$ with the corresponding coefficients calculated from the atmospheric observations $\left(K_{\text {obs }}\right)$ from environments with varying temperatures and levels of anthropogenic influence. By taking into account the modelled behaviour of $J_{\mathrm{A} 2 \mathrm{~B} 2}$ as a function of $\left[\mathrm{H}_{2} \mathrm{SO}_{4}\right]$, temperature and $\mathrm{RH}$, the atmospheric particle formation rate was reproduced more closely than with the traditional semiempirical formulae based on sulphuric acid concentration only. The formation rates of clusters with two sulphuric acid and two amine molecules with different amine compositions (DMA or TMA or one of both) had different responses to varying meteorological conditions and concentrations of 
vapours participating in particle formation. The observed inverse proportionality of the coefficient $K_{\mathrm{obs}}$ with $\mathrm{RH}$ and temperature agreed best with the modelled coefficient $K_{\mathrm{A} 2 \mathrm{~B} 2}$ related to formation of a cluster with two $\mathrm{H}_{2} \mathrm{SO}_{4}$ and one or two TMA molecules, assuming that these clusters can grow in collisions with abundant organic vapour molecules. In case this assumption is valid, our results suggest that the formation rate of clusters with at least two of both sulphuric acid and amine molecules might be the rate-limiting step for atmospheric particle formation. More generally, our analysis elucidates the sensitivity of the atmospheric particle formation rate to meteorological variables and concentrations of vapours participating in particle formation (also other than $\mathrm{H}_{2} \mathrm{SO}_{4}$ ).

\section{Introduction}

The formation of new aerosol particles and their growth has been observed to take place in a wide variety of environments (Kulmala et al., 2004; Kulmala and Kerminen, 2008; Mirme et al., 2010; Zhang et al., 2012). In terms of the total particle number concentration in the global atmosphere, particle formation is very likely to dominate over the primary aerosol particle sources (Spracklen et al., 2006; Yu et al., 2010). Atmospheric particle formation has been estimated to give a significant contribution the global cloud condensation nuclei budget (Spracklen et al., 2008; Merikanto et al., 2009; Pierce and Adams, 2009; Yu and Luo, 2009), and to cause significant uncertainties in estimates of both current and future indirect climate forcing by aerosols (Wang and Penner, 2009; Kazil et al., 2010; Makkonen et al., 2012).

The most important vapour for atmospheric new particle formation is thought to be sulphuric acid, yet significant uncertainties related to the actual formation mechanism and role of other vapours in this process remain (Kerminen et al., 2010; Sipilä et al., 2010; Kirkby et al., 2011; Zhang et al., 2012). Field measurements indicate that the formation rate of new aerosol particles tend to be proportional to the ambient sulphuric acid concentration $\left(\left[\mathrm{H}_{2} \mathrm{SO}_{4}\right]\right)$ to the power of 1-2 (Weber et al., 1996; Sihto et al., 2006; Riipinen et al., 2007; Kuang et al., 2008; Paasonen et al., 2010), but larger power values have also been presented (e.g. Wang et al., 2011). Theoretically, the power of one could be explained by an activation-type process (Kulmala et al., 2006) and the power of two by a kinetic process (McMurry and Friedlander, 1979). The corresponding semi-empirical expressions for the particle formation rate, $J$, may be written as:

$J=A\left[\mathrm{H}_{2} \mathrm{SO}_{4}\right]$

and

$J=K\left[\mathrm{H}_{2} \mathrm{SO}_{4}\right]^{2}$,

where $A$ and $K$ are empirically determined coefficients (e.g. Riipinen et al., 2007). It should be noted that the power of two can be explained also by other than kinetically limited processes (Vehkamäki et al., 2012).

At present, there is no general consensus on whether Eqs. (1) or (2) describes better the atmospheric particle formation, or should some more detailed parameterisation be used. This unfortunate situation stems from (i) the scarcity of atmospheric measurement data suitable for this purpose, (ii) challenges in analysing atmospheric particle formation events (Korhonen et al., 2011), (iii) the possibility of having more than one formation mechanism operating either simultaneously or under different atmospheric conditions, and (iv) the large variability of the empirically determined values of the coefficients $A$ and $K$ between different particle formation events and from site to site. In most of the previous studies the particle formation rate is compared only with the sulphuric acid concentration. The detailed role of other constituents and the impact of meteorological conditions are not known so far, even though the roles of organic vapours (e.g. Metzger et al., 2010) and relative humidity (Hamed et al., 2011) have been studied. In this manuscript we will investigate the variability of the coefficient $K$ and the factors possibly responsible for this variability. We will focus on the kinetic-type process (Eq. 2), since this mechanism is tractable with the modelling framework that we will use as our main analysis tool. Furthermore, Paasonen et al. (2010) showed that even though the coupling between particle formation rate and sulphuric acid concentration was roughly linear (as in Eq. 1) when the data from several sites were investigated together, the analysis of single-site data sets revealed closer to quadratic couplings at each site (as in Eq. 2).

In order to approach the problem, we need to specify the vapours participating in particle formation. Petäjä et al. (2011) showed that under atmospherically relevant conditions, the formation rate of sulphuric acid dimers is close to the collision rate of sulphuric acid molecules. In order to explain this finding, a stabilizing agent (most probably a basic molecule) is required in a sulphuric acid-containing cluster. Several laboratory experiments have pointed out that amines, which are probably the strongest bases present in atmosphere with significant concentrations, have a marked enhancing impact on particle formation (Murphy et al., 2007; Berndt et al., 2010; Erupe et al., 2011; Bzdek et al., 2011; Zhao et al., 2011; Yu et al., 2012). These observations agree with quantum chemical calculations, e.g. Kurtén et al. (2008), Loukonen et al. (2010) and Ortega et al. (2012) concluded that amines are far more efficient than ammonia in stabilizing small $\mathrm{H}_{2} \mathrm{SO}_{4}$-clusters in the atmosphere. However, Nadykto et al. (2011) estimated that the difference between amines and ammonia in their capacity for stabilizing $\mathrm{H}_{2} \mathrm{SO}_{4}$-clusters is evened out by typically orders of magnitude higher atmospheric ammonia concentrations. The formation of stable $\mathrm{H}_{2} \mathrm{SO}_{4}$ dimers is the first step in acid-base cluster formation, and thereby gives the maximum particle formation rate in the kinetic-type process. Hypothetically, it might be that a cluster of two $\mathrm{H}_{2} \mathrm{SO}_{4}$ and amine molecules could be both large 
and (relatively) basic enough to grow further via collisions with acids other than $\mathrm{H}_{2} \mathrm{SO}_{4}$ as well - for example organic acids, which have much higher atmospheric concentrations than sulphuric acid. In this case, the formation rate of the clusters would be directly comparable to the observed particle formation rate.

Even though some atmospheric concentration measurements have been made during the last decades (Ge et al., 2011; Hanson et al., 2011), the knowledge of the concentrations of gas phase amine molecules in ambient air is still far from being complete. Even less is known about the spatial and temporal variation of their concentrations. In addition, the insufficient understanding of the role of other organic vapours in particle formation or in their initial growth increases the uncertainties in determining the mechanism behind atmospheric particle formation.

The particle formation rate is expected to be affected by the ambient temperature and humidity. The evaporation rate of molecules from a cluster increases exponentially with the temperature, so the stability of clusters decreases with an increasing temperature and a smaller fraction of the clusters will be able to grow into larger sizes. On the other hand, the presence of water molecules increases the stability of some sulphuric acid-amine-clusters (Loukonen et al., 2010), and thus the particle formation rate can also depend on relative humidity (RH).

The coefficient $K$ has been observed to vary by roughly four orders of magnitude, from about $10^{-15}$ to $10^{-11} \mathrm{~cm}^{3} \mathrm{~s}^{-1}$ under different atmospheric conditions (Kuang et al., 2008; Paasonen et al., 2010). Our main goal in this paper is to shed light on the factors explaining this variability. More specifically, we aim to address the following questions: (i) how the formation rate of $\left(\mathrm{H}_{2} \mathrm{SO}_{4}\right)_{2}$-amine clusters (i.e. stabilized sulphuric acid dimers) is limited by the concentrations of $\mathrm{H}_{2} \mathrm{SO}_{4}$ and amines, (ii) how sensitive this process is to the properties of different amines, (iii) what the roles of ambient temperature and humidity are, and (iv) how our results compare with atmospheric observations. We model the concentrations of clusters formed from sulphuric acid and two amines, di- and trimethylamine, in atmospherically relevant concentration and temperature ranges. The model results are presented in the way that they are comparable to atmospheric measurements. In addition to the model results, we compare the modelled formation rate of stable dimers to a variety of atmospheric data of particle formation rate and sulphuric acid concentration measured in very different atmospheric environments.

\section{Materials and methods}

In the following sections the abbreviations $\mathrm{A}, \mathrm{D}$, and $\mathrm{T}$ refer to sulphuric acid $\left(\mathrm{H}_{2} \mathrm{SO}_{4}\right)$, dimethylamine $\left(\left(\mathrm{CH}_{3}\right)_{2} \mathrm{NH}\right.$, DMA), and trimethylamine $\left(\left(\mathrm{CH}_{3}\right)_{3} \mathrm{~N}\right.$, TMA), respectively. The abbreviation $\mathrm{B}$ refers to base, here meaning either DMA or TMA. The number of molecules in a cluster is marked with a subscript and the concentration is marked with square brackets, e.g. $\left[\mathrm{A}_{2} \mathrm{D}_{1} \mathrm{~T}_{1}\right]$ stands for the concentration of clusters with two sulphuric acid molecules, one DMA and one TMA molecule. Additionally we use $\left[\mathrm{A}_{1, \text { tot }}\right]$ for the total sulphuric acid monomer concentration, i.e. the sum of concentrations $[A],\left[A_{1} D_{1}\right]$ and $\left[A_{1} T_{1}\right]$. In the comparison between the model results and atmospheric observations we denote with $K_{\text {obs }}$ the values of the coefficient $K$ calculated from the measured particle formation rate and sulphuric acid concentration using Eq. (2).

\subsection{Model system}

The modelled cluster size space includes clusters consisting of $1 \ldots 3$ molecules of sulphuric acid and $0 \ldots 2$ amine molecules. However, the clusters $A_{3} T_{2}$ and $A_{3} D_{1} T_{1}$ were not included in the model, because the corresponding quantum chemical formation energies have not been calculated so far. Ortega et al. (2012) determined the cluster energies for clusters up to $\mathrm{A}_{4} \mathrm{D}_{4}$, but we did not include all of these clusters into our system in order to keep the model system similar for both DMA and TMA. Including the larger clusters would also require an assumption that e.g. the organic vapours do not adhere to these clusters (due to their too high acidity/low basicity), which would complicate the system further. The effect of water molecules bound to $A_{2}, A_{1} D_{1}$ and $A_{1} T_{1}$ clusters on the concentration distribution was studied, but the hydrated clusters were not directly included in the dynamic model (see Sect. 2.1.3 for how hydration was implicitly accounted for). The model runs were performed in temperature range from 260 to $320 \mathrm{~K}$ and $\mathrm{RH}$ range from 0 to $100 \%$.

The amine concentrations were kept constant during the model runs. We made the calculations with [DMA] to [TMA] ratios of $1: 1,1: 10$ and $10: 1$. In order to make the comparison to measured sulphuric acid concentration possible (see Sect. 2.1.1), we also kept the total sulphuric acid monomer concentration $\left[\mathrm{A}_{1, \text { tot }}\right]$ constant by fixing the changes in $[A]$ to be inverse to changes in $\left[\mathrm{A}_{1} \mathrm{~B}_{1}\right]$, i.e. $\mathrm{d}[\mathrm{A}] / \mathrm{d} t=-\mathrm{d}\left[\mathrm{A}_{1} \mathrm{D}_{1}\right] / \mathrm{d} t-\mathrm{d}\left[\mathrm{A}_{1} \mathrm{~T}_{1}\right] / \mathrm{d} t$.

\subsubsection{Kinetic model and rate coefficients}

We used a kinetic model (DACM; Kulmala, 2010) for calculating the concentrations of sulphuric acid-amine-clusters. The steady state concentrations were determined by dynamical equations for each cluster. The time derivatives of the concentration of each cluster type included source terms from the collisions and evaporations resulting in that cluster. The sink terms originated from the evaporation rates from the cluster, its collisions with the other clusters or molecules within the model and losses due to the coagulation sink, which was set equal to $10^{-3} \mathrm{~s}^{-1}$, a typical sink for molecular sized clusters in continental background areas (Dal Maso et al., 2007). The steady state cluster concentrations were 
calculated with the ode15s solver in MATLAB program. This solver is effective for solving stiff differential equations (Shampine and Reichelt, 1997). With the solver, the concentrations of clusters are changed according to the above described time derivatives repeatedly until the steady state of the whole system is achieved.

The collision rates $k_{i j}$ between clusters $i$ and $j$ were calculated as (Seinfeld and Pandis, 2006)

$k_{i j}=\beta_{i j} c_{i} c_{j}$,

where $c_{i}$ stands for the concentration of cluster $i$, and $\beta_{i j}$ is the collision coefficient between clusters $i$ and $j$, obtained from kinetic gas theory as

$\beta_{i j}=\pi\left(r_{i}+r_{j}\right)^{2} \sqrt{\frac{8 k_{B} T}{\pi \mu}}$,

where $k_{B}$ is the Boltzmann constant, $T$ is the temperature, $r_{i}$ is the radius of cluster $i$ and $\mu=m_{i} m_{j} /\left(m_{i}+m_{j}\right)$ is the reduced mass.

The evaporation $e_{i+j \rightarrow i, j}$ rates were calculated as

$e_{i+j \rightarrow i, j}=\gamma_{i+j \rightarrow i, j} c_{i+j}$,

where $\gamma_{i+j \rightarrow i, j}$ is the evaporation coefficient of cluster $i+j$ evaporating into clusters $i$ and $j$, and $c_{i+j}$ is the concentration of cluster $i+j$. The evaporation coefficients were acquired from the quantum chemical calculations described by Ortega et al. (2012). Assuming detailed balance, the evaporation coefficient can be calculated from the corresponding collision coefficient and the Gibbs free energies of formation of the evaporating cluster $i+j$ and the product clusters $i$ and $j$ :

$\gamma_{i+j \rightarrow i, j}=\beta_{i j} \frac{p_{\text {ref }}}{k_{B} T} \exp \left(\frac{\Delta G_{i+j}-\Delta G_{i}-\Delta G_{j}}{k_{B} T}\right)$,

where $\beta_{i j}$ is the collision coefficient, $\Delta G_{i}$ is the Gibbs free energy of formation from monomers of cluster $i$ and $p_{\text {ref }}$ is the reference pressure where the formation free energies have been calculated (which cancels because the values of $\Delta G_{i}$ are calculated in the same pressure).

The formation free energies of all the clusters were originally calculated at $298.15 \mathrm{~K}$ using a quantum chemical multi-step method that combines B3LYP/CBSB7 optimized geometry and frequency calculations with RI-CC2/aug-cc$\mathrm{pV}(\mathrm{T}+\mathrm{d}) \mathrm{Z}$ single point energy calculations (Ortega et al., 2012). The Gibbs free energy of formation in other temperatures was calculated as

$\Delta G=\Delta H+T \Delta S$,

where $\Delta H$ and $\Delta S$ are the formation enthalpy and entropy of formation of the cluster, respectively, obtained using harmonic oscillator and rigid rotor approximations for the clusters. The values of $\Delta H$ and $\Delta S$ were assumed to be constant over the studied temperature range. This assumption is reasonable, as e.g. for the $\mathrm{A}_{2} \mathrm{~T}_{2}$-cluster the maximum difference between $\Delta G$ s calculated with constant and temperature dependent values of $\Delta H$ and $\Delta S$ is, within the studied temperature range, around $0.01 \mathrm{kcal} \mathrm{mol}^{-1}$.

Some assumptions of the evaporation rates were necessary to be made because quantum chemical free energies for all the relevant larger clusters were not available. The rate coefficients for the following collisions were set to zero, because the reverse evaporation from the resulting cluster occurs presumably very rapidly (Ortega et al., 2012): all collisions of the type $\mathrm{A}_{1} \mathrm{~B}_{2}+\mathrm{B} ; \mathrm{A}_{3}+\mathrm{A}_{n} ; \mathrm{A}_{3} \mathrm{~B}_{1}+\mathrm{A}_{n} ; \mathrm{A}_{2} \mathrm{~T}_{2}+$ $\mathrm{T}$ (as the computed evaporation rate of DMA from $\mathrm{A}_{2} \mathrm{D}_{3}$ is very fast, see Sect. 3.1). However, the collisions leading to clusters $A_{2} D_{2} T_{1}$ and $A_{2} D_{1} T_{2}$ were allowed. Even though these two clusters are very unstable, they may form different evaporation products than the initial clusters/molecules that collided: e.g. whether a DMA or TMA molecule evaporates from $\mathrm{A}_{2} \mathrm{D}_{2} \mathrm{~T}_{1}$ cluster does not depend on the conformation of the colliders $\left(\mathrm{A}_{2} \mathrm{D}_{2}+\mathrm{TMA}\right.$ or $\left.\mathrm{A}_{2} \mathrm{D}_{1} \mathrm{~T}_{1}+\mathrm{DMA}\right)$, but it is determined by the relative stabilities of the end products after the evaporation, $\mathrm{A}_{2} \mathrm{D}_{2}$ and $\mathrm{A}_{2} \mathrm{D}_{1} \mathrm{~T}_{1}$ (this results from applying Eq. (6) for calculating the ratio of two evaporation rates from the same initial cluster, i.e. with same $\Delta G_{i+j}$, the differences between the collision rates $\beta_{2 \mathrm{~A} 2 \mathrm{~B}+\mathrm{B}}$ for different amines $\mathrm{B}$ being negligible, and the monomer energies $\Delta G_{\mathrm{DMA}}$ and $\Delta G_{\mathrm{TMA}}$ equal to zero, by definition). We have not computed the free energies for clusters $\mathrm{A}_{2} \mathrm{D}_{2} \mathrm{~T}_{1}$ and $A_{2} D_{1} T_{2}$, but, as it is obvious that they are very unstable, they were set to evaporate one of the amines (the identity of which is determined by the relative stabilities of the potential remaining clusters) instantaneously when formed. Similar base substitution reactions for clusters containing ammonia have been studied by Kupiainen et al. (2012) and for charged clusters by Bzdek et al. (2010) and DePalma et al. (2011).

With the above presented boundary conditions, all the routes along which the clusters grow out of the system are included in the formation rate of clusters with two or more molecules of both A and B, $J_{\mathrm{A} 2 \mathrm{~B} 2}$ (see Sect. 2.1.4). We repeated all the model runs under the assumption that the $\mathrm{A}_{2} \mathrm{~B}_{2}$-clusters also grow out of the system by collisions with organic vapour molecules having concentration of $10^{9} \mathrm{~cm}^{-3}$. These collisions were included in the model by adding an additional loss term for the $\mathrm{A}_{2} \mathrm{~B}_{2}$-clusters.

\subsubsection{Effect of cluster formation on sulphuric acid concentration}

The atmospheric sulphuric acid concentration is typically measured with Chemical Ionization Mass Spectrometers (CIMS; Berresheim et al., 2000; Petäjä et al., 2009; Sjöstedt et al., 2007). The measurement with the CIMS is based on selective ionization, during which the reagent nitrate ions (and/or its clusters with nitric acid) accept a proton from sulphuric acid molecule, converting it to a bisulphate ion. The 
signal of these bisulphate ions in the mass spectrometer is then converted to concentration via the calibration method described by Mauldin III et al. (1999). However, Kurtén et al. (2011) calculated that at least a significant portion of the $\mathrm{H}_{2} \mathrm{SO}_{4}$ - ammonia- and $\mathrm{H}_{2} \mathrm{SO}_{4}$. DMA-clusters gets charged in the CIMS charger. This charging leads to an immediate evaporation of the base molecule, and thus these clusters are detected as pure $\mathrm{H}_{2} \mathrm{SO}_{4}$. In order to take this into account, we modelled the $\mathrm{H}_{2} \mathrm{SO}_{4}$ concentration measurement with the total concentration of sulphuric acid monomers, i.e. the sum of the pure sulphuric acid monomer concentration and the concentration of $\mathrm{A}_{1} \mathrm{~B}_{1}$-clusters

$\left[\mathrm{A}_{1, \mathrm{tot}}\right]=[\mathrm{A}]+\left[\mathrm{A}_{1} \mathrm{~T}_{1}\right]+\left[\mathrm{A}_{1} \mathrm{D}_{1}\right]$.

We ran the model with $\left[\mathrm{A}_{1, \text { tot }}\right]$ in range of $10^{5}$ to $3.16 \times 10^{8} \mathrm{~cm}^{-3}$, covering the typical observed ambient sulphuric acid concentrations (Petäjä et al., 2009; Mikkonen et al., 2011; Zheng et al., 2011).

\subsubsection{Effect of water on the collision and evaporation rates}

The concentration of water in the atmosphere is approximately ten orders of magnitude higher than those of sulphuric acid, ammonia and amines, and solving the birth-death equations for the full (three-dimensional) water-containing system is, therefore, computationally very challenging. To overcome this problem, we first solved the hydrate distributions for clusters with no more than two molecules (other than water) at different temperatures and relative humidities, and then calculated effective collision and evaporation rates of the other compounds as a weighted average over these hydrate distributions.

The hydrate distributions for a cluster $\mathrm{C}$ were solved with (see e.g. Kurtén et al., 2007)

$$
f\left(\mathrm{CW}_{i}\right)=\frac{\left[\mathrm{CW}_{i}\right]}{\sum_{j=0}^{j_{\max }}\left[\mathrm{CW}_{j}\right]},
$$

where $\mathrm{C}$ is a molecule or a cluster of two molecules other than water, $\mathrm{W}$ stands for water, $\mathrm{CW}_{i}$ is $\mathrm{C}$ clustered with $i$ water molecules, and

$$
\frac{\left[\mathrm{CW}_{i}\right]}{[\mathrm{C}]}=\left([\mathrm{W}] \frac{k_{B} T}{p_{0}}\right)^{i} \exp \left(\frac{\Delta G(\mathrm{C})-\Delta G\left(\mathrm{CW}_{i}\right)}{k_{B} T}\right),
$$

where $[\mathrm{W}]$ is the concentration of water vapor and $p_{0}$ is the reference pressure (in this case $1 \mathrm{~atm}$ ) in which the Gibbs free energies are calculated. The effective collision rates were calculated by averaging over the hydrate distributions as

$\beta_{\mathrm{eff}}(\mathrm{C}+\mathrm{D})=\sum_{i=0}^{i_{\max }} \sum_{j=0}^{j_{\max }} \beta\left(\mathrm{CW}_{i}+\mathrm{DW}_{j}\right) f\left(\mathrm{CW}_{i}\right) f\left(\mathrm{DW}_{j}\right)$,

and effective evaporation rates similarly as

$$
\begin{aligned}
& \gamma_{\mathrm{eff}}(\mathrm{CD} \rightarrow \mathrm{C}+\mathrm{D}) \\
& \quad=\sum_{i=0}^{i_{\max }} \sum_{j=0}^{j_{\max }} \gamma\left(\mathrm{CDW}_{i+j} \rightarrow \mathrm{CW}_{i}+\mathrm{DW}_{j}\right) f\left(\mathrm{CDW}_{i+j}\right) .
\end{aligned}
$$

We performed test simulations of individual collision and evaporation processes, where we took all hydrates of the reactants and products explicitly into account. We found that the hydrate distribution of each species remained in equilibrium during the process, and the resulting effective collision and evaporation rates were in agreement with Eqs. (11) and (12). Therefore, all the simulations in this study with $\mathrm{RH}>0$ have been performed assuming that the hydrate distributions of all molecules and clusters equilibrate much faster than the timescales of other collision, evaporation or coagulation processes. Thus, water molecules have not been included explicitly in the simulations, but through the effective collision and evaporation rates.

\subsubsection{Modelled cluster formation rate}

The minimum requirement for a cluster to participate in particle formation is that it holds together long enough to collide with another cluster or molecule of nucleating vapour. We modelled the formation rate of a cluster as the difference between the sum of collision rates forming the cluster and the sum of evaporation rates from the cluster, i.e.

$J_{a b}=\sum k_{\left(a_{\mathrm{i}} b_{i}\right)\left(a_{j} b_{j}\right)}\left[a_{i} b_{i}\right]\left[a_{j} b_{j}\right]-\sum \gamma_{a b}[a b]$,

where the first term describes the formation of clusters with at least $a$ acid molecules and $b$ base molecules from the collisions of all the clusters $a_{i} b_{i}$ and $a_{j} b_{j}$ in which $a_{i}+a_{j} \geq a$ and $b_{i}+b_{j} \geq b$, and the second term describes the evaporation rate as a sum of the rates at which an acid or base molecule or an acid-base-cluster is evaporated from cluster $a b$. This approach is analogous to the measured particle formation rates (e.g. Manninen et al., 2009; Kulmala et al., 2012), in which the external loss terms for a particle, coagulation and growth, are also taken into account.

In this study, we examine in detail $J_{\mathrm{A} 2 \mathrm{~B} 2}$, the formation rate of clusters including two or more sulphuric acid molecules and two or more amine molecules (for clarification, here are listed some of the collisions that are counted in $J_{\mathrm{A} 2 \mathrm{~B} 2}: \mathrm{A}_{2} \mathrm{~B}_{1}+\mathrm{B} ; \mathrm{A}_{1} \mathrm{~B}_{1}+\mathrm{A}_{1} \mathrm{~B}_{1} ; \mathrm{A}_{1} \mathrm{~B}_{2}+\mathrm{A}_{2} ; \mathrm{A}_{2} \mathrm{~B}_{1}+\mathrm{A}_{2} \mathrm{~B}_{1}$, but e.g. $A_{2} B_{2}+A$ is not, because the formation of $A_{2} B_{2}$ is already counted in $\left.J_{\mathrm{A} 2 \mathrm{~B} 2}\right)$. The conversions of $\mathrm{A}_{2} \mathrm{~T}_{2}, \mathrm{~A}_{2} \mathrm{D}_{1} \mathrm{~T}_{1}$ and $\mathrm{A}_{2} \mathrm{D}_{2}$ due to their collisions with amine molecules, described in Sect. 2.1.2, were taken into account when calculating formation rates $J_{\mathrm{A} 2 \mathrm{~B} 2}$. Thus, we subtracted e.g. from the formation rate $J_{\mathrm{A} 2 \mathrm{~T} 2}$ calculated with Eq. (13) the proportion of collisions $A_{2} T_{2}+D$ which results in $A_{2} D_{1} T_{1}$, and consistently added this proportion to $J_{\mathrm{A} 2 \mathrm{D} 1 \mathrm{~T} 1}$. The evaporations reckoned in the calculation of $J_{\mathrm{A} 2 \mathrm{~B} 2}$ are those from 
$A_{2} B_{2}$-clusters only, because the evaporation rates of $A_{\geq 1} B_{\geq 1}$ from most of the $\mathrm{A}_{>2} \mathrm{~B}_{\geq 2}$-clusters were not available (following consequences are discussed in Sect. 5.1). The reason for not analysing separately the formation rate of $\mathrm{A}_{2} \mathrm{~B}_{1}$ clusters $\left(J_{\mathrm{A} 2 \mathrm{~B} 1}\right)$ will be explained later.

The formation rate $J_{\mathrm{A} 2 \mathrm{~B} 2}$ is, as shown in the results, coupled with $\left[\mathrm{A}_{1, \text { tot }}\right]$ to the power close to two. In order to study the effects of varying temperature, $\mathrm{RH}$ and concentrations of $\mathrm{H}_{2} \mathrm{SO}_{4}$ and amines on $J_{\mathrm{A} 2 \mathrm{~B} 2}$, we inspect the behaviour of the "observable" coefficient $K_{\mathrm{A} 2 \mathrm{~B} 2}$ in

$$
J_{\mathrm{A} 2 \mathrm{~B} 2}=K_{\mathrm{A} 2 \mathrm{~B} 2}\left[\mathrm{~A}_{1, \text { tot }}\right]^{2} \text {. }
$$

\subsection{Atmospheric measurements}

We reanalysed nine sets of measurements from around the Northern Hemisphere, all including data for aerosol particle number size distribution, sulphuric acid concentration, temperature and RH. The sulphuric acid concentrations at all the sites were measured with CIMS instruments. The measurements in Hyytiälä (Finland) were conducted at the SMEAR II station during QUEST II- and QUEST IV-campaigns in March-April 2003 and April-May 2005, respectively (Sihto et al., 2006; Riipinen et al., 2007), and during the EUCAARIcampaign in April-May 2007 (Kulmala et al., 2011). The measurements at the German stations, Melpitz in May 2008 and Hohenpeissenberg from June 2007 to December 2008, were also conducted as a part of the EUCAARI campaign, as well as the measurements at San Pietro Capofiume (Italy) during June-July 2009. The data at Tecamác (municipality $40 \mathrm{~km}$ north from Mexico City, Mexico) were gathered in May 2006 (Iida et al., 2008), at Atlanta (US) (McMurry and Eisele, 2005; Kuang et al., 2008) in August 2002 and at Beijing (China) between July and September 2008 (Wang et al., 2011).

The particle number size distribution measurements during the EUCAARI campaigns (Hyytiälä 2007, Melpitz, Hohenpeissenberg and S. P. Capofiume) were measured with a Neutral and Air Ion Spectrometer (NAIS, Kulmala et al., 2007). From these data the formation rate of particles with diameter of $2 \mathrm{~nm}$ was calculated directly by the method of Paasonen et al. (2010). At the other sites the particle number size distribution was measured with a Differential Mobility Particle Sizer (DMPS). From these data we calculated first the formation rate of $4 \mathrm{~nm}$ particles using a similar procedure as with the NAIS data, and then back calculated the formation rate of $2 \mathrm{~nm}$ particles with the formula given by Kerminen and Kulmala (2002). From the QUEST campaigns in Hyytiälä we applied the data for the formation rate of $1.5 \mathrm{~nm}$ particles calculated with the methods described by Sihto et al. (2006) and Riipinen et al. (2007).

\section{Results: simulated behaviour of the system}

\subsection{Cluster formation free energies and evaporation rates}

The quantum chemical enthalpies $\Delta H$, entropies $\Delta S$ and the related Gibbs free energies $\Delta G$ at $T=280 \mathrm{~K}$ of the clusters included in the model are presented in Table 1 . The resulting evaporation rates are presented in Table 2 , and those of $A_{1} B_{1}, A_{2} B_{2}$ and $A_{2} B_{1}$-clusters are depicted in Fig. 1a. Electronic cluster formation energies calculated in this study (at the B3LYP/CBSB7//RI-CC2/aug-cc-pV(T+d)Z level) as well as the coordinates of the most stable structure of each cluster (at the B3LYP/CBSB7 level) are presented in the Supplement. The same information for the other clusters is presented by Ortega et al. (2012). Additionally, the figures illustrating the chemical structure of the most stable $\mathrm{A}_{2} \mathrm{D}_{2}, \mathrm{~A}_{2} \mathrm{~T}_{2}$ and $A_{2} D_{1} T_{1}$-clusters are presented in the Supplement.

Evaporation from $\mathrm{A}_{3} \mathrm{~B}_{1}$-clusters was found to be very fast in comparison to $\mathrm{A}_{2} \mathrm{~B}_{1}$-clusters (see Table 2), and adding more acids while keeping the number of bases constant would increase the evaporation rate even more (Ortega et al., 2012). This implies that in order to form a stable cluster consisting of at least two $\mathrm{H}_{2} \mathrm{SO}_{4}$ molecules that is capable of growing further, the addition of a second base molecule is required. Thus, we focus on the formation of clusters consisting of at least two molecules of both sulphuric acid and amine molecules.

Trimethylamine is a stronger base than dimethylamine, making the $A_{1} T_{1}$-cluster slightly more stable than the $A_{1} D_{1}$ cluster. However, the nitrogen atom in the TMA molecule, already bound to three carbon atoms, is capable of forming only one hydrogen bond, whereas that in dimethylamine can form two. Thus, the $\mathrm{A}_{2} \mathrm{~T}_{2}$-cluster is much less stable than $\mathrm{A}_{2} \mathrm{D}_{2}$ cluster. Accordingly, the only crucial point in the formation of $A_{2} D_{2}$ is whether the $A_{1} D_{1}$-cluster will hold together until it collides with another cluster or a sulphuric acid molecule. In the formation of $\mathrm{A}_{2} \mathrm{~T}_{2}$-clusters, also the competition between the evaporation of TMA from $\mathrm{A}_{2} \mathrm{~T}_{2}$ cluster and the collision of $\mathrm{A}_{2} \mathrm{~T}_{2}$ with the next condensing molecule is important. It should be noted that the evaporation of a TMA molecule from a $\mathrm{A}_{2} \mathrm{~T}_{2}$-cluster results in a very stable $\mathrm{A}_{2} \mathrm{~T}_{1}$-cluster which can then grow back by colliding either with an amine molecule or $\mathrm{H}_{2} \mathrm{SO}_{4}$ clustered with an amine molecule.

The relative stabilities of $A_{1} T_{1}$ - and $A_{1} D_{1}$-clusters change when water molecules are introduced to the system. The effective evaporation rates from these clusters, and from $\mathrm{A}_{2}$ cluster for comparison, are presented as a function of $\mathrm{RH}$ in Fig. 1b. In typical atmospheric conditions $(T=280 \mathrm{~K}$, $\mathrm{RH}=40 \%$ ) the water molecule concentration is around $10^{17} \mathrm{~cm}^{-3}$, leading to a collision frequency with water of about $5 \times 10^{7} \mathrm{~s}^{-1}$ for all molecules and clusters. As the evaporation rate of water from the $\mathrm{A}_{1} \mathrm{D}_{1} \mathrm{~W}_{1}$-cluster is of the same order of magnitude (see right hand side in Table 2), 
Table 1. Formation enthalpies $\Delta H$ and entropies $\Delta S$, calculated at $298 \mathrm{~K}$, and the corresponding Gibbs free energies $\Delta G$ at $T=280 \mathrm{~K}$. The values of $\Delta H$ and $\Delta G$ are given in $\left[\mathrm{kcal} \mathrm{mol}^{-1}\right]$, and $\Delta S$ in $\left[\mathrm{cal} \mathrm{mol}^{-1} \mathrm{~K}^{-1}\right.$ ].

\begin{tabular}{lrrrlrrr}
\hline Cluster & $\Delta H$ & $\Delta S$ & $\Delta G$ & Cluster & $\Delta H$ & $\Delta S$ & $\Delta G$ \\
\hline $\mathrm{A}_{2}$ & -17.85 & -33.42 & -8.49 & $\mathrm{~A}_{1} \mathrm{~W}_{1}$ & -11.34 & -29.70 & -3.02 \\
$\mathrm{~A}_{3}$ & -35.82 & -72.19 & -15.61 & $\mathrm{~A}_{1} \mathrm{~W}_{2}$ & -22.49 & -60.69 & -5.50 \\
$\mathrm{~A}_{1} \mathrm{D}_{1}$ & -24.65 & -31.01 & -15.97 & $\mathrm{~A}_{1} \mathrm{~W}_{3}$ & -33.89 & -100.19 & -5.84 \\
$\mathrm{~A}_{2} \mathrm{D}_{1}$ & -57.06 & -74.40 & -36.23 & $\mathrm{~A}_{1} \mathrm{~W}_{4}$ & -45.97 & -131.91 & -9.04 \\
$\mathrm{~A}_{3} \mathrm{D}_{1}$ & -81.46 & -112.90 & -49.85 & $\mathrm{~A}_{1} \mathrm{~W}_{5}$ & -54.74 & -160.16 & -9.89 \\
$\mathrm{~A}_{1} \mathrm{D}_{2}$ & -40.08 & -66.37 & -21.5 & $\mathrm{~A}_{2} \mathrm{~W}_{1}$ & -31.64 & -68.74 & -12.39 \\
$\mathrm{~A}_{2} \mathrm{D}_{2}$ & -87.52 & -105.16 & -58.08 & $\mathrm{~A}_{2} \mathrm{~W}_{2}$ & -45.67 & -106.43 & -15.87 \\
$\mathrm{~A}_{3} \mathrm{D}_{2}$ & -113.58 & -155.37 & -70.08 & $\mathrm{~A}_{2} \mathrm{~W}_{3}$ & -57.35 & -136.68 & -19.08 \\
$\mathrm{~A}_{2} \mathrm{D}_{3}$ & -108.24 & -152.75 & -65.47 & $\mathrm{~A}_{2} \mathrm{~W}_{4}$ & -68.27 & -168.62 & -21.06 \\
$\mathrm{~A}_{1} \mathrm{~T}_{1}$ & -26.04 & -34.54 & -16.37 & $\mathrm{~A}_{2} \mathrm{~W}_{5}$ & -82.95 & -208.44 & -24.59 \\
$\mathrm{~A}_{2} \mathrm{~T}_{1}$ & -57.16 & -75.30 & -36.08 & $\mathrm{D}_{1} \mathrm{~W}_{1}$ & -6.65 & -28.43 & 1.31 \\
$\mathrm{~A}_{3} \mathrm{~T}_{1}$ & -75.32 & -112.92 & -43.70 & $\mathrm{D}_{1} \mathrm{~W}_{2}$ & -15.80 & -66.40 & 2.79 \\
$\mathrm{~A}_{1} \mathrm{~T}_{2}$ & -42.23 & -71.66 & -22.17 & $\mathrm{~A}_{1} \mathrm{D}_{1} \mathrm{~W}_{1}$ & -37.89 & -65.76 & -19.48 \\
$\mathrm{~A}_{2} \mathrm{~T}_{2}$ & -84.48 & -118.41 & -51.33 & $\mathrm{~A}_{1} \mathrm{D}_{1} \mathrm{~W}_{2}$ & -48.79 & -99.37 & -20.97 \\
$\mathrm{~A}_{1} \mathrm{D}_{1} \mathrm{~T}_{1}$ & -41.01 & -68.15 & -21.93 & $\mathrm{~A}_{1} \mathrm{D}_{1} \mathrm{~W}_{3}$ & -58.81 & -134.40 & -21.18 \\
$\mathrm{~A}_{2} \mathrm{D}_{1} \mathrm{~T}_{1}$ & -83.86 & -113.64 & -52.04 & $\mathrm{~A}_{1} \mathrm{D}_{1} \mathrm{~W}_{4}$ & -69.46 & -164.94 & -23.28 \\
& & & & $\mathrm{~A}_{1} \mathrm{D}_{1} \mathrm{~W}_{5}$ & -80.10 & -199.35 & -24.28 \\
& & & & $\mathrm{~A}_{1} \mathrm{~T}_{1} \mathrm{~W}_{1}$ & -35.52 & -66.46 & -16.91 \\
& & & & $\mathrm{~A}_{1} \mathrm{~T}_{1} \mathrm{~W}_{2}$ & -45.20 & -95.26 & -18.53 \\
\hline
\end{tabular}

Table 2. Evaporation rates from the modelled clusters at $T=280 \mathrm{~K}$ in units $\left[\mathrm{s}^{-1}\right]$. The highest evaporation rate from each cluster type is indicated with bold font.

\begin{tabular}{|c|c|c|c|c|c|c|c|c|c|c|}
\hline \multirow{2}{*}{$\begin{array}{l}\text { Initial } \\
\text { cluster }\end{array}$} & \multicolumn{5}{|c|}{ Evaporated molecule/cluster } & \multirow{2}{*}{$\begin{array}{l}\text { Initial } \\
\text { cluster }\end{array}$} & \multicolumn{4}{|c|}{ Evaporated molecule } \\
\hline & A & $\mathrm{D}$ & $\mathrm{A}_{1} \mathrm{D}_{1}$ & $\mathrm{~T}$ & $\mathrm{~A}_{1} \mathrm{~T}_{1}$ & & $\mathrm{~W}$ & $\mathrm{~A}_{1} \mathrm{~W}_{n}$ & $\mathrm{D}$ & $\mathrm{T}$ \\
\hline $\mathrm{A}_{2}$ & $2 \times 10^{3}$ & - & - & - & - & $\mathrm{A}_{1} \mathrm{~W}_{1}$ & $5 \times 10^{7}$ & $5 \times 10^{7}$ & - & - \\
\hline $\mathrm{A}_{3}$ & $3 \times 10^{4}$ & - & - & - & - & $\mathrm{A}_{1} \mathrm{~W}_{2}$ & $2 \times 10^{8}$ & $2 \times 10^{8}$ & - & - \\
\hline$A_{1} D_{1}$ & $4 \times 10^{-3}$ & $4 \times 10^{-3}$ & - & - & - & $\mathrm{A}_{2}$ & - & $2 \times 10^{3}$ & - & - \\
\hline $\mathrm{A}_{2} \mathrm{D}_{1}$ & $2 \times 10^{-6}$ & $3 \times 10^{-12}$ & $2 \times 10^{-6}$ & - & - & $\mathrm{A}_{2} \mathrm{~W}_{1}$ & $1 \times 10^{7}$ & $5 \times 10^{2}$ & - & - \\
\hline$A_{3} D_{1}$ & $3 \times 10^{-1}$ & $3 \times 10^{-17}$ & $2 \times 10^{-10}$ & - & - & $\mathrm{A}_{2} \mathrm{~W}_{2}$ & $3 \times 10^{7}$ & $2 \times 10^{2}$ & - & - \\
\hline$A_{1} D_{2}$ & $7 \times 10^{-10}$ & $7 \times 10^{5}$ & $7 \times 10^{5}$ & - & - & $\mathrm{A}_{2} \mathrm{~W}_{3}$ & $5 \times 10^{7}$ & $6 \times 10^{1}$ & - & - \\
\hline$A_{2} D_{2}$ & $3 \times 10^{-19}$ & $1 \times 10^{-7}$ & $5 \times 10^{-11}$ & - & - & $\mathrm{A}_{2} \mathrm{~W}_{4}$ & $5 \times 10^{8}$ & $2 \times 10^{2}$ & - & - \\
\hline$A_{3} D_{2}$ & $5 \times 10^{0}$ & $3 \times 10^{-6}$ & $1 \times 10^{-4}$ & - & - & $\mathrm{A}_{1} \mathrm{D}_{1}$ & - & $4 \times 10^{-3}$ & $4 \times 10^{-3}$ & - \\
\hline $\mathrm{A}_{2} \mathrm{D}_{3}$ & $1 \times 10^{-20}$ & $3 \times 10^{4}$ & $2 \times 10^{-12}$ & - & - & $\mathrm{A}_{1} \mathrm{D}_{1} \mathrm{~W}_{1}$ & $3 \times 10^{7}$ & $2 \times 10^{-3}$ & $2 \times 10^{-3}$ & _- \\
\hline $\mathrm{A}_{1} \mathrm{~T}_{1}$ & $2 \times 10^{-3}$ & - & - & $2 \times 10^{-3}$ & - & $\mathrm{A}_{1} \mathrm{D}_{1} \mathrm{~W}_{2}$ & $1 \times 10^{9}$ & $1 \times 10^{-2}$ & $1 \times 10^{-2}$ & - \\
\hline $\mathrm{A}_{2} \mathrm{~T}_{1}$ & $4 \times 10^{-6}$ & - & - & $4 \times 10^{-12}$ & $4 \times 10^{-6}$ & $\mathrm{~A}_{1} \mathrm{~T}_{1}$ & - & $2 \times 10^{-3}$ & - & $2 \times 10^{-3}$ \\
\hline $\mathrm{A}_{3} \mathrm{~T}_{1}$ & $1 \times 10^{4}$ & - & - & $2 \times 10^{-12}$ & $2 \times 10^{-5}$ & $\mathrm{~A}_{1} \mathrm{~T}_{1} \mathrm{~W}_{1}$ & $6 \times 10^{9}$ & $2 \times 10^{-1}$ & - & $2 \times 10^{-1}$ \\
\hline$A_{1} T_{2}$ & - & - & - & $4 \times 10^{5}$ & $4 \times 10^{5}$ & $\mathrm{~A}_{1} \mathrm{~T}_{1} \mathrm{~W}_{2}$ & $9 \times 10^{8}$ & $1 \times 10^{0}$ & - & $1 \times 10^{0}$ \\
\hline $\mathrm{A}_{2} \mathrm{~T}_{2}$ & $2 \times 10^{-13}$ & - & - & $2 \times 10^{-2}$ & $4 \times 10^{-5}$ & & & & & \\
\hline $\mathrm{A}_{1} \mathrm{D}_{1} \mathrm{~T}_{1}$ & - & $7 \times 10^{5}$ & $3 \times 10^{5}$ & $3 \times 10^{5}$ & $7 \times 10^{5}$ & & & & & \\
\hline $\mathrm{A}_{2} \mathrm{D}_{1} \mathrm{~T}_{1}$ & $4 \times 10^{-14}$ & $6 \times 10^{-3}$ & $5 \times 10^{-6}$ & $7 \times 10^{-3}$ & $5 \times 10^{-6}$ & & & & & \\
\hline
\end{tabular}

a large fraction of $\mathrm{A}_{1} \mathrm{D}_{1} \mathrm{~W}_{n}$-clusters is hydrated. Because the $A_{1} D_{1} W_{1}$ is more stable than $A_{1} D_{1} W_{0}$, one would expect decrease in the effective evaporation rate of DMA from $\mathrm{A}_{1} \mathrm{D}_{1} \mathrm{~W}_{n}$-clusters with increasing $\mathrm{RH}$. However, this decrease is visible only at low RHs after which the rate remains constant or even slightly increases. This feature is caused by a small proportion (up to $10 \%$ at $\mathrm{RH}=100 \%$ ) of $\mathrm{A}_{1} \mathrm{D}_{1} \mathrm{~W}_{n}$-clusters having two water molecules at higher RH. This relatively unstable cluster evaporates DMA more efficiently than the less hydrated ones, thus increasing the effective evaporation rate. Unlike in case of $\mathrm{A}_{1} \mathrm{D}_{1} \mathrm{~W}_{1}$, the evaporation rate of a water molecule from $A_{1} T_{1} W_{1}$ clusters is two orders of magnitude higher than the typical collision rate with water molecules. Therefore only $2 \%$ of all 

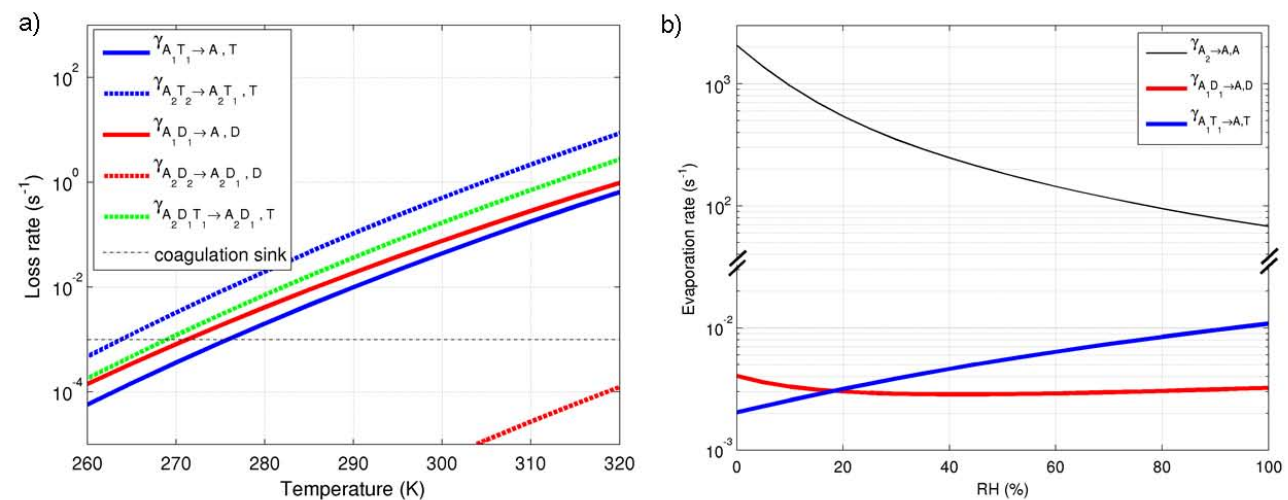

Fig. 1. (a) Evaporation rates from $A_{1} B_{1}, A_{2} B_{2}$ and $A_{2} B_{1}$-clusters as a function of temperature at $R H=0$. The presented evaporation rates are the highest rates corresponding to each cluster (see Table 2). The coagulation rate used in the model is depicted for comparison. (b) Effective evaporation rates from $\mathrm{A}_{2}$ and $\mathrm{A}_{1} \mathrm{~B}_{1}$-clusters at their equilibrium hydrate distributions as a function of $\mathrm{RH}$ at $T=280 \mathrm{~K}$. Note the splitting of the scale.

$\mathrm{A}_{1} \mathrm{~T}_{1} \mathrm{~W}_{n}$ clusters are hydrated even at $\mathrm{RH}=100 \%$. This minor fraction, however, increases the effective evaporation rate of TMA from $\mathrm{A}_{1} \mathrm{~T}_{1} \mathrm{~W}_{n}$-clusters, because the evaporation of a TMA molecule is 100 times faster from the $\mathrm{A}_{1} \mathrm{~T}_{1} \mathrm{~W}_{1}$-cluster compared to that from $A_{1} T_{1}$. As a result, the effective evaporation rate of a TMA molecule from $\mathrm{A}_{1} \mathrm{~T}_{1} \mathrm{~W}_{n}$-clusters is higher than that of a DMA molecule from $\mathrm{A}_{1} \mathrm{D}_{1} \mathrm{~W}_{n}$-clusters at $\mathrm{RH}$ of $20 \%$ and higher.

Due to the large computational costs, we did not calculate the quantum chemical free energies of clusters consisting of water and more than two other molecules. For these clusters we assumed that they would evaporate water molecules so effectively that the proportion of hydrated clusters is negligible, and does not affect the effective evaporation rate of a sulphuric acid or amine molecule. This has been shown to be a relevant assumption for the sulphuric acid $\mathrm{A}_{2} \mathrm{D}_{1}$ clusters (Loukonen et al., 2010). Because the TMA molecule is capable of forming only one hydrogen bond, a $A_{>1} T_{\geq 1}$ cluster (where water can make bonds only with the acid molecules) should bind with water even less strongly than a $\mathrm{A}_{>1} \mathrm{D}_{\geq 1}$-cluster. This is consistent with the far higher evaporation rates of water from the $A_{1} T_{1} W_{1}$-cluster than from the $A_{1} D_{1} W_{1}$-cluster (see Table 2). Thus, the presence of water molecules should not significantly affect the evaporation rates calculated for clusters with more than two sulphuric acid or amine molecules.

\subsection{Sulphuric acid monomer distribution}

We present first the results acquired with a [DMA] to [TMA] ratio of one, and describe in Sect. 3.3.4 how the results change if either concentration is higher.

As our goal in this study is to model the formation rate of $\mathrm{H}_{2} \mathrm{SO}_{4}$-amine-clusters with respect to the sulphuric acid concentration measured with CIMS (approximated to equal the total sulphuric acid monomer concentration $\left.\left[\mathrm{A}_{1, \text { tot }}\right]\right)$, we first inspect the proportions of pure and clustered sulphuric acid monomers. In Fig. 2a we depict the fractions of pure $\mathrm{H}_{2} \mathrm{SO}_{4}$ molecules (solid lines with circles), $\mathrm{A}_{1} \mathrm{~T}_{1}$-clusters (solid lines) and $\mathrm{A}_{1} \mathrm{D}_{1}$-clusters (dashed lines) of the total monomer concentration $\left[\mathrm{A}_{1, \text { tot }}\right]$ under varying amine concentrations as a function of $\left[\mathrm{A}_{1, \text { tot }}\right]$ at $T=280 \mathrm{~K}$ and in absence of water. When $\left[\mathrm{A}_{1, \text { tot }}\right]$ is below $10^{6} \mathrm{~cm}^{-3}$ (and the meteorological conditions are as above), the fraction of sulphuric acid monomers being clustered with an amine molecule depends only on the amine concentration, but when $\left[\mathrm{A}_{1, \text { tot }}\right]$ surpasses $10^{6} \mathrm{~cm}^{-3}$ the clustered fraction starts decreasing. If the amine concentration is $10^{8} \mathrm{~cm}^{-3}$ or higher and an order of magnitude higher than $\left[\mathrm{A}_{1, \text { tot }}\right]$, almost all of the monomers are clustered with amines, $>30 \%$ with DMA and $>60 \%$ with TMA.

The monomer concentration distribution is strongly dependent on the temperature (Fig. 2b). The fraction of $\mathrm{H}_{2} \mathrm{SO}_{4}$ clustered with amines starts decreasing at temperatures $>270 \mathrm{~K}$, as the evaporation rate from $\mathrm{A}_{1} \mathrm{~B}_{1}$-clusters exceeds the coagulation sink. However, when the amine concentration increases and exceeds $\left[\mathrm{A}_{1, \text { tot }}\right]$, the temperature at which this decrease becomes visible is elevated, because the increasing collision frequency between sulphuric acid and amine molecules fastens the reformation of the evaporated clusters. In addition to the prevailing concentrations and temperature, the monomer concentration distribution is affected by RH (Fig. 2c). At temperatures below $270 \mathrm{~K}$ (or at high $\left.\left[\mathrm{A}_{1, \text { tot }}\right]\right)$, the effect of RH is insignificant as evaporation is not the main sink for the clustered monomers. At higher temperatures, concentration $\left[\mathrm{A}_{1} \mathrm{~T}_{1}\right]$ becomes smaller than $\left[\mathrm{A}_{1} \mathrm{D}_{1}\right]$ when $\mathrm{RH}$ exceeds $20 \%$. Above this $\mathrm{RH}$, the proportion of $\mathrm{A}_{1} \mathrm{~T}_{1}$ clusters continues decreasing with $\mathrm{RH}$ while the proportion of (hydrated) pure acid molecules increases.

At amine concentrations $>10^{7} \mathrm{~cm}^{-3}$, the fraction of $\mathrm{A}_{1} \mathrm{D}_{1}$-clusters is lower than that of $\mathrm{A}_{1} \mathrm{~T}_{1}$-clusters also at temperatures at which the evaporation rates of both are below 

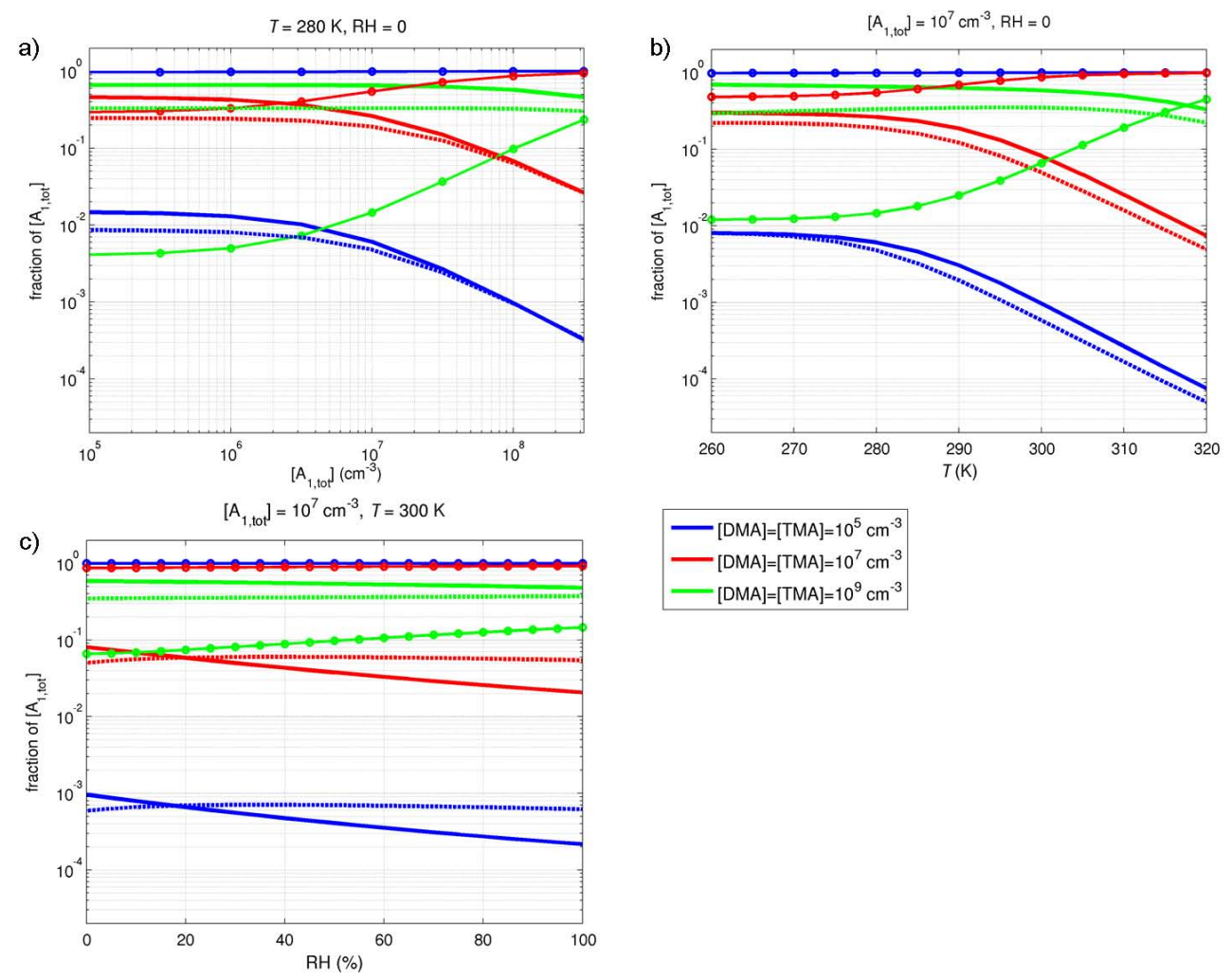

Fig. 2. Contributions of pure $A$ (solid lines with circles), $A_{1} T_{1}$-cluster (solid lines) and $A_{1} D_{1}$-cluster (dashed lines) to the total $\mathrm{H}_{2} \mathrm{SO}_{4}$ monomer concentration $\left[\mathrm{A}_{1}\right.$,tot $]$ at varying amine concentrations (a) as a function of the total $\mathrm{H}_{2} \mathrm{SO}_{4}$ monomer concentration, (b) as a function of temperature and (c) as a function of relative humidity $(\mathrm{RH})$. Temperatures, $\mathrm{RHs}$ and total sulphuric acid monomer concentrations in the model runs are shown in the panels.

the coagulation sink, and thus the loss rates are equal. This feature arises from the slight stability difference between the $A_{1} T_{1} W_{0}$ and $A_{1} D_{1} W_{0}$-clusters: under high amine concentrations the $\mathrm{A}_{1} \mathrm{D}_{1}\left(\mathrm{~W}_{n}\right)$-clusters collide frequently with TMA-molecules, and due to the higher stability of the $\mathrm{A}_{1} \mathrm{~T}_{1} \mathrm{~W}_{0}$-cluster in comparison with $\mathrm{A}_{1} \mathrm{D}_{1} \mathrm{~W}_{0}$, the formed, very unstable $A_{1} D_{1} T_{1}$-cluster evaporates more often DMA than TMA. Via this mechanism, a significant fraction of $A_{1} D_{1}$-clusters are continuously converted to $A_{1} T_{1}$-clusters.

\subsection{Modelled formation rates $J_{\mathrm{A} 2 \mathrm{~B} 2}$ and the corresponding coefficients $K_{\mathrm{A} 2 \mathrm{~B} 2}$}

In the following we will consider only the formation rate of $\mathrm{A}_{\geq 2} \mathrm{~B}_{\geq 2}$-clusters, $J_{\mathrm{A} 2 \mathrm{~B} 2}$, calculated with Eq. (14). The formation rate $J_{\mathrm{A} 2 \mathrm{~B} 1}$ is not presented separately, because the high evaporation rate of $\mathrm{A}$ from $\mathrm{A}_{3} \mathrm{~B}_{1}$ (see Table 2) does not allow the $A_{2} B_{1}$-clusters to grow further before the addition of the second amine. The collisions of $\mathrm{A}_{2} \mathrm{~B}_{1}$ with amine containing clusters are, instead, counted in $J_{\mathrm{A} 2 \mathrm{~B} 2}$. The modelled formation rates of clusters with at least two $\mathrm{H}_{2} \mathrm{SO}_{4}$ and amine molecules are presented in Fig. 3 as a function of the modelled total sulphuric acid monomer concentration $\left[\mathrm{A}_{1, \text { tot }}\right]$ under varying amine concentration with the [DMA] : [TMA] ratio equal to unity.

As an overall result, it is notable that all the modelled formation rates are coupled with the concentration $\left[\mathrm{A}_{1, \text { tot }}\right]$ to the power close to two, as can be seen by comparing them with the $\mathrm{A}_{1, \text { tot }}$ collision rate, $4.5 \times 10^{-10} \cdot\left[\mathrm{A}_{1, \text { tot }}\right]^{2}$, indicated in Fig. 3 with a solid black line. However, the power of $\left[A_{1, \text { tot }}\right]$ with which the formation rates $J_{\mathrm{A} 2 \mathrm{~B} 2}$ are connected varies slightly from two: e.g. $J_{\mathrm{A} 2 \mathrm{~T} 2}$ is steeper than the collision rate at low values of $\left[\mathrm{A}_{1, \text { tot }}\right]$ and gentler at high $\left[\mathrm{A}_{1, \text { tot }}\right]$. A detailed analysis explaining the deviation of the powers from two and the decreasing formation rates $J_{\mathrm{A} 2 \mathrm{~T} 2}$ with increasing amine concentrations are given in the following sections.

\subsubsection{Effect of temperature}

The ambient temperature has an obvious impact on the fraction of sulphuric acid monomers being clustered with amines (Fig. 2b). The formation rate of $\mathrm{A}_{2} \mathrm{~B}_{2}$-clusters is strongly dependent on this fraction, because pure sulphuric acid molecules do not form stable dimers. Since the information of the clusterization of the sulphuric acid monomers is lost when the sulphuric acid concentration is measured with the CIMS (see Sect. 2.1.2), the formation rate of $\mathrm{A}_{2} \mathrm{~B}_{2}$ - 


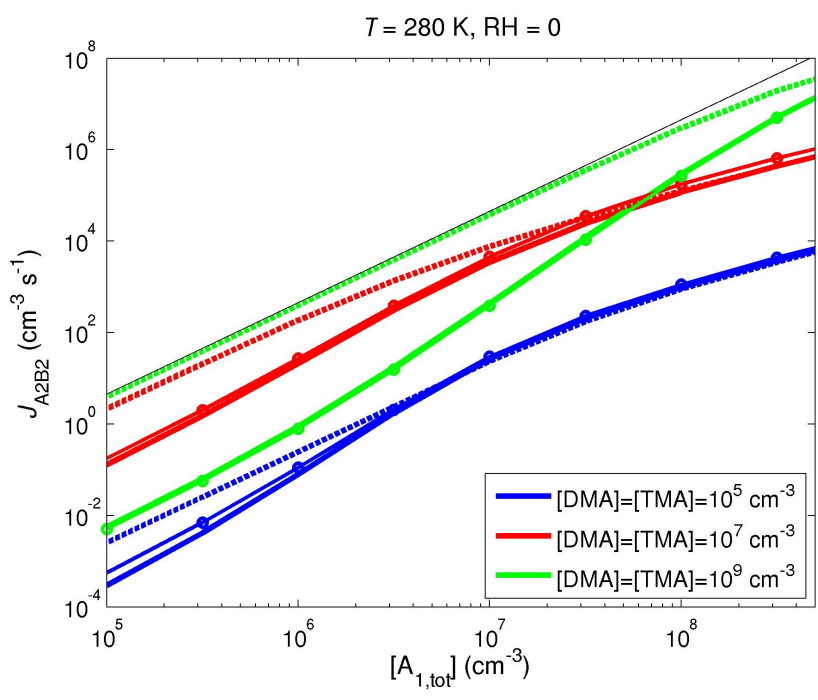

Fig. 3. The modelled formation rates $J_{\mathrm{A} 2 \mathrm{~T} 2}$ (solid lines), $J_{\mathrm{A} 2 \mathrm{D} 2}$ (dashed lines) and $J_{\mathrm{A} 2 \mathrm{D} 1 \mathrm{~T} 1}$ (solid lines with circles) as a function of the modelled total sulphuric acid monomer concentration [A 1, tot $]$ at $T=280 \mathrm{~K}$ under varying amine concentration with a $1: 1$ [DMA] : [TMA]-ratio. The solid black line represents the collision rate $4.5 \times 10^{-10} \mathrm{~cm}^{3} \mathrm{~s}^{-1} \cdot\left[\mathrm{A}_{1, \mathrm{tot}}\right]^{2}$ calculated for all the $\mathrm{H}_{2} \mathrm{SO}_{4}$ monomers.

clusters can be expected to be affected by the varying temperature at a given value of $\left[\mathrm{A}_{1, \text { tot }}\right]$ comparable to the measured $\mathrm{H}_{2} \mathrm{SO}_{4}$ concentration. We studied this temperature effect by inspecting the temperature dependence of the coefficient $K_{\mathrm{A} 2 \mathrm{~B} 2}$, calculated from Eq. (14) as $K_{\mathrm{A} 2 \mathrm{~B} 2}=J_{\mathrm{A} 2 \mathrm{~B} 2} /\left[\mathrm{A}_{1, \text { tot }}\right]^{2}$.

To get an impression of the temperature and monomer concentration dependences of the coefficients $K_{\mathrm{A} 2 \mathrm{~T} 2}$ and $K_{\mathrm{A} 2 \mathrm{D} 2}$, we first depict them as functions of temperature in the presence of only one amine (Fig. 4). The crucial factors affecting the value of $K_{\mathrm{A} 2 \mathrm{~B} 2}$ are the amine concentration and the values of the different sink terms, i.e. the evaporation rate, coagulational sink rate and collision rate of the $\mathrm{A}_{2} \mathrm{~B}_{2}$-cluster with sulphuric acid monomers and dimers (either clustered with amine or not), the latter determining the further growth of the $\mathrm{A}_{2} \mathrm{~B}_{2}$-clusters.

In principle $K_{\mathrm{A} 2 \mathrm{~T} 2}$ and $K_{\mathrm{A} 2 \mathrm{D} 2}$ behave similarly. If we first inspect the lowest temperatures in Fig. 4, we can see that the collision rate of $A_{1, \text { tot }}\left(\sim 4.5 \times 10^{-10} \mathrm{~cm}^{3} \mathrm{~s}^{-1}\right)$ is achieved when the amine concentration is roughly an order of magnitude higher than $\left[\mathrm{A}_{1, \text { tot }}\right]$. The other main feature is the decrease of $K_{\mathrm{A} 2 \mathrm{~B} 2}$ as a function of temperature due to the decreasing proportion of clustered sulphuric acid monomers (see Fig. $2 \mathrm{~b}$ ). A third similarity between $K_{\mathrm{A} 2 \mathrm{~T} 2}$ and $K_{\mathrm{A} 2 \mathrm{D} 2}$ is that at the lowest temperatures the values of both coefficients decrease with increasing $\left[\mathrm{A}_{1, \text { tot }}\right]$. This decrease in the coefficients $K_{\mathrm{A} 2 \mathrm{~B} 2}$ leads to an interesting result: at low temperatures, the formation rate $J_{\mathrm{A} 2 \mathrm{~B} 2}$ increases slower than quadratically as a function of $\left[\mathrm{A}_{1, \text { tot }}\right]$, denoted as $J_{\mathrm{A} 2 \mathrm{~B} 2} \sim\left[\mathrm{A}_{1, \text { tot }}\right]^{<2}$.
Despite the qualitatively similar behaviour of $K_{\mathrm{A} 2 \mathrm{~T} 2}$ and $K_{\mathrm{A} 2 \mathrm{D} 2}$ in varying concentration and temperature space, there are some notable differences between Fig. 4a and b. First of all, the exponential decrease of $K_{\mathrm{A} 2 \mathrm{~B} 2}$ as a function of temperature is much steeper for TMA than for DMA: for a temperature increase of $30 \mathrm{~K}$ the coefficient $K_{\mathrm{A} 2 \mathrm{~T} 2}$ decreases roughly four orders of magnitude, but $K_{\mathrm{A} 2 \mathrm{D} 2}$ only about two orders of magnitude. The steep decrease of $K_{\mathrm{A} 2 \mathrm{~T} 2}$ as a function of temperature results from the reversed temperature dependencies of the source and the sink of $\mathrm{A}_{2} \mathrm{~T}_{2}$-clusters: the source decreases with temperature, due to increased evaporation of $\mathrm{A}_{1} \mathrm{~T}_{1}$-clusters, whereas the main sink, the evaporation rate from $\mathrm{A}_{2} \mathrm{~T}_{2}$-clusters, increases. In case of $\mathrm{A}_{2} \mathrm{D}_{2}$-clusters, the decrease in the source rate is similar, but the evaporation from $\mathrm{A}_{2} \mathrm{D}_{2}$ is smaller than the other sink terms over the whole studied temperature range, and the total sink does not change significantly with temperature.

Another difference between Fig. $4 \mathrm{a}$ and b is that $K_{\mathrm{A} 2 \mathrm{~T} 2}$ is strongly dependent on $\left[\mathrm{A}_{1, \text { tot }}\right]$ also at high temperatures (lines corresponding to same [TMA] but different $\left[\mathrm{A}_{1, \text { tot }}\right]$ are separated also at $T>300 \mathrm{~K}$ ), whereas the values of $K_{\mathrm{A} 2 \mathrm{D} 2}$ corresponding to the same [DMA] are not significantly different at high temperatures. This difference originates from different outcome of the competition between the growth and evaporation for different $\mathrm{A}_{2} \mathrm{~B}_{2}$-clusters. Due to the high stability of $\mathrm{A}_{2} \mathrm{D}_{2}$, practically all of the formed $\mathrm{A}_{2} \mathrm{D}_{2}$-clusters collide with $\left[\mathrm{A}_{1, \text { tot }}\right]$ before evaporating even at $\left[\mathrm{A}_{1, \text { tot }}\right]=10^{6} \mathrm{~cm}^{-3}$. On the contrary, a TMA molecule is evaporated from most of the $A_{2} T_{2}$ clusters before collision growth at temperatures above $290 \mathrm{~K}$ at all studied concentrations $\left[A_{1, \text { tot }}\right]$. Consequently, an increase in $\left[A_{1, \text { tot }}\right]$ increases the probability of $\mathrm{A}_{2} \mathrm{~T}_{2}$-cluster growth before the evaporation of TMA, leading to over an order of magnitude increase in $K_{\mathrm{A} 2 \mathrm{~T} 2}$ due to an order of magnitude increase in $\left[\mathrm{A}_{1, \text { tot }}\right]$. Thus, at high temperatures $J_{\mathrm{A} 2 \mathrm{~T} 2} \sim\left[\mathrm{A}_{1, \text { tot }}\right]^{>3}$.

The values of $K_{\mathrm{A} 2 \mathrm{D} 2}$ are for the most part independent of $\left[\mathrm{A}_{1, \text { tot }}\right]$ at high temperatures, but when $\left[\mathrm{A}_{1, \text { tot }}\right]$ reaches values over two orders of magnitude higher than [DMA] (as in the blue solid lines with circles in Fig. $4 \mathrm{~b}$ ) the coefficient $K_{\mathrm{A} 2 \mathrm{D} 2}$ starts increasing. With such a large difference in monomer concentrations, $\left[\mathrm{A}_{2} \mathrm{D}_{1}\right]$ becomes higher than [DMA] and thus the collisions between two $\mathrm{A}_{2} \mathrm{D}_{1}$ clusters become a significant source term for $J_{\mathrm{A} 2 \mathrm{D} 2}$. The same occurs in the case of TMA cluster formation as well (blue lines in Fig. 4a). This feature and its significance should be considered with caution, due to the opposite, presumably rapid, evaporations of $\mathrm{A}_{2} \mathrm{~B}_{1}$-clusters from the resulting $\mathrm{A}_{4} \mathrm{~B}_{2}$-cluster, which are not included in our model (Ortega et al., 2012; more detailed discussion in Sect. 5.1).

\subsubsection{Effect of amine competition}

The modelled coefficients $K_{\mathrm{A} 2 \mathrm{~B} 2}$ related to different $\mathrm{A}_{2} \mathrm{~B}_{2}$ clusters, when both the amines are present with a concentration ratio of $1: 1$, are depicted as a function of temperature 

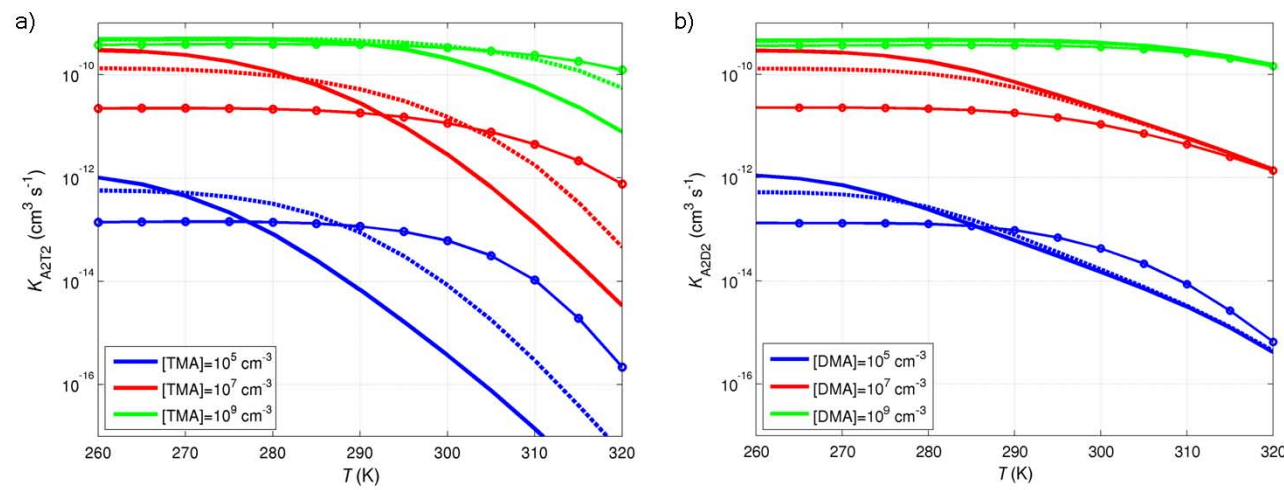

Fig. 4. The modelled coefficients $K_{22}$, the ratio of $J_{22}$ and squared total sulphuric acid monomer concentration, as a function of temperature for (a) $\mathrm{A}_{2} \mathrm{~T}_{2}$-clusters and (b) $\mathrm{A}_{2} \mathrm{D}_{2}$-clusters in cases when only one amine is present. The solid lines correspond to total $\mathrm{H}_{2} \mathrm{SO}_{4}$ monomer concentration $\left[\mathrm{A}_{1, \text { tot }}\right]=10^{6} \mathrm{~cm}^{-3}$, the dashed to $\left[\mathrm{A}_{1, \text { tot }}\right]=10^{7} \mathrm{~cm}^{-3}$ and the solid lines with circles to $\left[\mathrm{A}_{1, \text { tot }}\right]=10^{8} \mathrm{~cm}-3$.
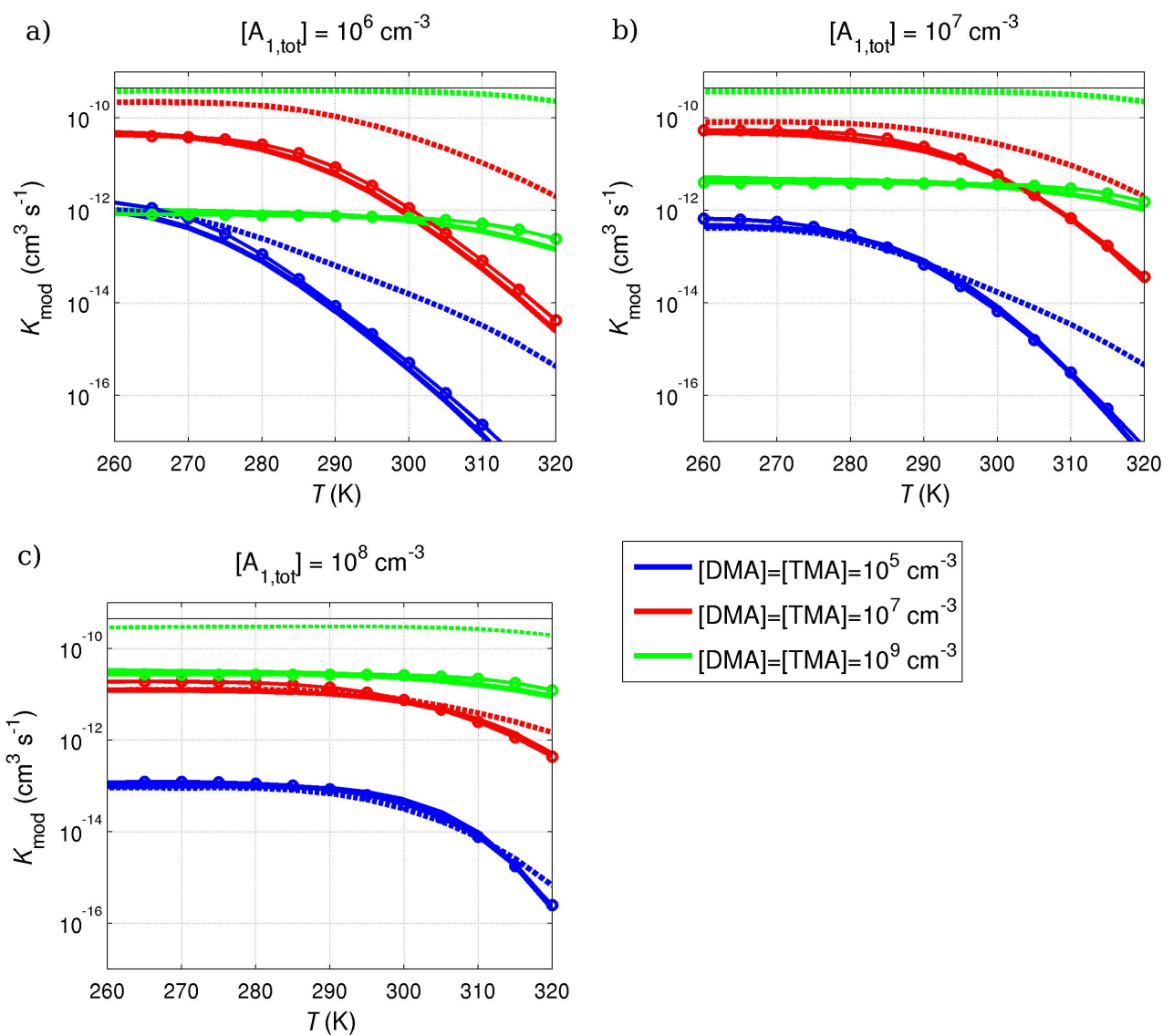

Fig. 5. Modelled coefficients $K_{22}$, the ratio of $J_{22}$ and squared total sulphuric acid monomer concentration, as a function of temperature under DMA to TMA ratio $1: 1$ (concentrations shown in the legend), when the total sulphuric acid monomer concentration [ $\left.\mathrm{A}_{1, \text { tot }}\right]$ equals to (a) $10^{6} \mathrm{~cm}^{-3} \mathrm{~s}^{-1}$, (b) $10^{7} \mathrm{~cm}^{-3} \mathrm{~s}^{-1}$ and (c) $10^{8} \mathrm{~cm}^{-3} \mathrm{~s}^{-1}$. Solid lines correspond to $K_{\mathrm{A} 2 \mathrm{~T} 2}$, the dashed lines to $K_{\mathrm{A} 2 \mathrm{D} 2}$ and the solid lines with circles to $K_{\mathrm{A} 2 \mathrm{D} 1 \mathrm{~T} 1}$. The black line shows the collision rate of all $\mathrm{H}_{2} \mathrm{SO}_{4}$ monomers.

in Fig. 5, corresponding to $\left[\mathrm{A}_{1, \text { tot }}\right]$ equal to $10^{6}$ (Fig. 5a), $10^{7}$ (Fig. 5b) and $10^{8} \mathrm{~cm}^{-3}$ (Fig. 5c).

Even though the concentration of $\mathrm{A}_{1} \mathrm{~T}_{1}$-clusters is larger than that of $A_{1} D_{1}$-clusters at $R H=0$ (see Sect. 3.2), the for- mation rates $J_{\mathrm{A} 2 \mathrm{~B} 2}$ are dominated by the formation rate of clusters with two DMAs, $J_{\mathrm{A} 2 \mathrm{D} 2}$. The values of $K_{\mathrm{A} 2 \mathrm{D} 2}$ at an amine concentration ratio $1: 1$ are practically the same as those obtained in the absence of TMA (see Fig. 4b). At amine 


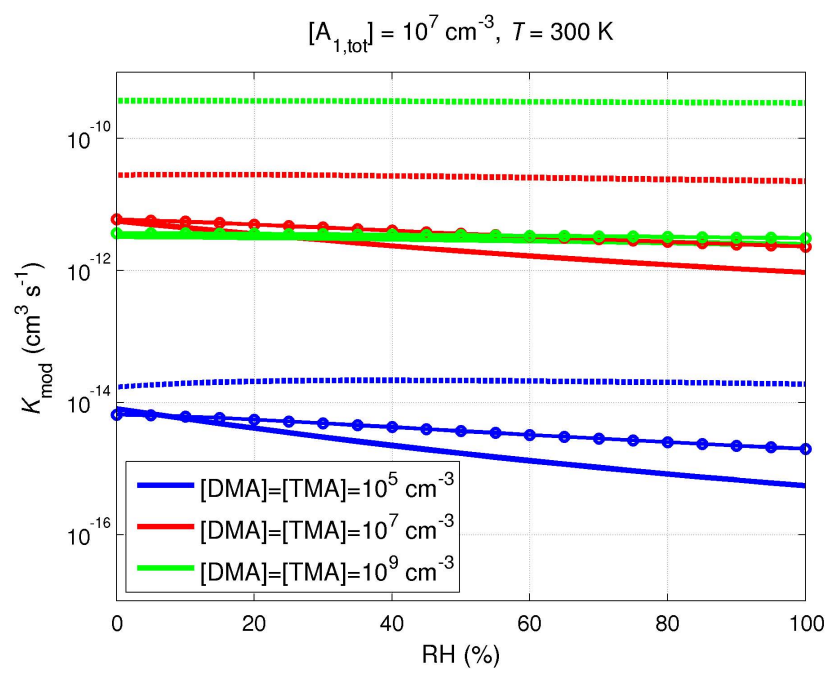

Fig. 6. The modelled coefficients $K_{22}$ as functions of relative humidity (RH). Solid lines correspond to $K_{\mathrm{A} 2 \mathrm{~T} 2}$, the dashed lines to $K_{\mathrm{A} 2 \mathrm{D} 2}$ and the solid lines with circles to $K_{\mathrm{A} 2 \mathrm{D} 1 \mathrm{~T} 1}$.

concentrations below or equal to $\left[\mathrm{A}_{1, \text { tot }}\right]$, the formation rate $J_{\mathrm{A} 2 \mathrm{~T} 2}$ is also very similar to that computed in the absence of DMA, but when the amine concentrations exceed the sulphuric acid monomer concentration by over an order of magnitude the value of $K_{\mathrm{A} 2 \mathrm{~T} 2}$ starts to decrease with increasing amine concentrations at temperatures below $\sim 300 \mathrm{~K}$. This feature is caused by a similar conversion mechanism to that of converting $A_{1} D_{1}$-clusters to more stable $A_{1} T_{1}$ clusters via $A_{1} D_{1} T_{1}$. The cluster $A_{2} D_{2}$ is $\sim 7 \mathrm{kcal} \mathrm{mol}^{-1}$ more stable than $A_{2} T_{2}$, whereas the $A_{2} D_{1} T_{1}$-cluster is less than one kcal mol${ }^{-1}$ more stable than $\mathrm{A}_{2} \mathrm{~T}_{2}$ (see Table 1). Because the evaporation rate depends on the stability difference between the initial and final cluster(s), the evaporated amine from $\mathrm{A}_{2} \mathrm{D}_{1} \mathrm{~T}_{2}$-clusters is DMA in $\sim 22 \%$ of evaporations, but from $\mathrm{A}_{2} \mathrm{D}_{2} \mathrm{~T}_{1}$-clusters DMA is evaporated in only $\sim 0.002 \%$ of evaporations. With this mechanism $\mathrm{A}_{2} \mathrm{~T}_{2}$ clusters are converted to $A_{2} D_{1} T_{1}$ and then to $A_{2} D_{2}$ by collisions with DMA. The higher the amine concentrations is, the more efficient the conversion.

The values and the temperature dependence of the coefficient $K_{\mathrm{A} 2 \mathrm{D} 1 \mathrm{~T} 1}$ are very similar to those of $K_{\mathrm{A} 2 \mathrm{~T} 2}$, the difference between the values of these two coefficients never exceeding a factor of two.

\subsubsection{Effect of relative humidity}

The effect of RH on the values of the modelled coefficients $K_{\mathrm{A} 2 \mathrm{~B} 2}$ at total sulphuric acid monomer concentration of $10^{7} \mathrm{~cm}^{-3}$ and $300 \mathrm{~K}$ is presented in Fig. 6. The effect of $\mathrm{RH}$ arises from the changes in the effective evaporation rate from the smallest clusters (see Sect 3.1). Thus, as stated in Sect. 3.2, the effect of RH is negligible at low temperatures or high $\left[\mathrm{A}_{1, \text { tot }}\right]$, when evaporation is not the main sink for these clusters.

The differences between the coefficients $K_{\mathrm{A} 2 \mathrm{D} 2}, K_{\mathrm{A} 2 \mathrm{D} 1 \mathrm{~T} 1}$ and $K_{\mathrm{A} 2 \mathrm{~T} 2}$ become more pronounced with an increasing RH. The increasing effective evaporation rate of $A_{1} T_{1}$ clusters decreases the formation rates of $\mathrm{A}_{2} \mathrm{~T}_{2}$ and $\mathrm{A}_{2} \mathrm{D}_{1} \mathrm{~T}_{1}$ on average by factors of 1.7 and 1.3 , respectively, per $20 \%$-units increases in $\mathrm{RH}$. The value of $K_{\mathrm{A} 2 \mathrm{D} 2}$ is practically independent of RH.

\subsubsection{Effect of varying DMA to TMA ratios}

In order to inspect the effect of varying the [DMA] to [TMA] ratio we repeated the analysis by setting $[\mathrm{DMA}]$ an order of magnitude higher or lower than [TMA].

The behaviour of the modelled coefficient $K_{\mathrm{A} 2 \mathrm{D} 2}$ in varying temperature and concentration space is affected only slightly by changes in the [DMA] to [TMA] ratio. Even if the concentration of DMA is an order of magnitude lower than the TMA concentration, the values of the coefficient $K_{\mathrm{A} 2 \mathrm{D} 2}$ remain almost equal to those in the case of one-to-one amine concentration ratio at $\left[\mathrm{A}_{1, \text { tot }}\right]=10^{6} \mathrm{~cm}^{-3}$, and decrease only by a factor up to four when $\left[\mathrm{A}_{1, \text { tot }}\right]$ increases to $10^{8} \mathrm{~cm}^{-3}$. If instead [TMA] is an order of magnitude lower than [DMA], the values of $K_{\mathrm{A} 2 \mathrm{D} 2}$ remain the same as in the absence of TMA at all conditions. On the contrary, the formation rate of $\mathrm{A}_{2} \mathrm{~T}_{2}$ clusters is strongly dependent on the amine concentration ratio. Similarly to the one-to-one amine concentration ratio, the coefficient $K_{\mathrm{A} 2 \mathrm{~T} 2}$ is practically equal to that in absence of DMA, as long as the DMA concentration is smaller than or equal to $\left[\mathrm{A}_{1, \text { tot }}\right]$. However, when [DMA] exceeds [A 1 ,tot], the increase of the value of $K_{\mathrm{A} 2 \mathrm{~T} 2}$ with increasing amine concentrations first stalls and then starts decreasing as [DMA] increases. This decrease at high DMA concentrations is caused by the higher probability of a $\mathrm{A}_{2} \mathrm{~T}_{2}$ cluster to collide with a DMA molecule than with a sulphuric acid monomer, leading to a conversion chain $\mathrm{A}_{2} \mathrm{~T}_{2} \rightarrow \mathrm{A}_{2} \mathrm{D}_{1} \mathrm{~T}_{1}$ $\rightarrow \mathrm{A}_{2} \mathrm{D}_{2}$, as explained in Sect. 3.3.2. Thus, in comparison to a [DMA] to [TMA] ratio of one-to-one (Fig. 5a-c), the stalling of $K_{\mathrm{A} 2 \mathrm{~T} 2}$ occurs at an order of magnitude higher [TMA] for a ratio $1: 10$, and with the opposite concentration ratio at an order of magnitude smaller [TMA]. Consequently, at a $10: 1$ ratio the values of $K_{\mathrm{A} 2 \mathrm{~T} 2}$ are below $2 \times 10^{-12} \mathrm{~cm}^{-3}$ at all the amine concentrations and temperatures. With this amine concentration ratio the value of the coefficient $K_{\mathrm{A} 2 \mathrm{D} 1 \mathrm{~T} 1}$ is a factor from 3 to 15 larger than the value of $K_{\mathrm{A} 2 \mathrm{~T} 2}$ at all conditions. With a [DMA] to [TMA] ratio of $1: 10 K_{\mathrm{A} 2 \mathrm{D} 1 \mathrm{~T} 1}$ is a factor from 4 to 12 smaller than $K_{\mathrm{A} 2 \mathrm{~T} 2}$. With both ratios the smallest values of $K_{\mathrm{A} 2 \mathrm{D} 1 \mathrm{~T} 1}$ correspond to the highest amine concentrations. The exponential decrease of $K_{\mathrm{A} 2 \mathrm{D} 1 \mathrm{~T} 1}$ with increasing temperature is still similar to that of $K_{\mathrm{A} 2 \mathrm{~T} 2}$ and thus clearly steeper than that of $K_{\mathrm{A} 2 \mathrm{D} 2}$. 


\subsubsection{Assuming organic vapours can adhere to $\mathbf{A}_{2} \mathbf{B}_{2}$-clusters}

As shown in Sect. 3.3.1 the formation rates $J_{\mathrm{A} 2 \mathrm{~T} 2}, J_{\mathrm{A} 2 \mathrm{D} 1 \mathrm{~T} 1}$ and $J_{\mathrm{A} 2 \mathrm{D} 2}$ are coupled with sulphuric acid concentration to power between below two and slightly over three, depending on the temperature and the ratio of $\left[\mathrm{A}_{1, \text { tot }}\right]$ to amine concentration. With the DACM model we can also investigate the outcomes of the assumption that two sulphuric acid molecules would be enough to form a cluster capable of growing by collisions with organic vapour molecules. If the concentration of this organic vapour is clearly higher than $\left[A_{1, \text { tot }}\right]$, the growth of the $A_{2} B_{2}$-clusters is no longer strongly dependent on $\left[\mathrm{A}_{1, \text { tot }}\right]$, but rather on the organic vapour concentration. We studied the changes in the behaviour of the coefficients $K_{\mathrm{A} 2 \mathrm{~B} 2}$ in case where $\mathrm{A}_{2} \mathrm{~B}_{2}$-clusters grow further (and do not evaporate back) via collisions with an organic vapour of concentration $10^{9} \mathrm{~cm}^{-3}$, which is well in the range of the typical total atmospheric organic acid concentrations (Chebbi and Carlier, 1996).

The organic vapour concentration has a negligible influence on the values of $K_{\mathrm{A} 2 \mathrm{D} 2}$, because even without organic vapours the evaporation of $\mathrm{A}_{2} \mathrm{D}_{2}$-clusters does not significantly decrease the formation rate $J_{\mathrm{A} 2 \mathrm{D} 2}$. However, the behaviour of $K_{\mathrm{A} 2 \mathrm{~T} 2}$ and $K_{\mathrm{A} 2 \mathrm{D} 1 \mathrm{~T} 1}$ changes if the growth of the related $\mathrm{A}_{2} \mathrm{~B}_{2}$-clusters can also occur by collisions with abundant organic vapour molecules. In Fig. 7 we have depicted the values of $K_{\mathrm{A} 2 \mathrm{~T} 2}$ at $1: 1$ amine concentration ratio resulting from the assumption that the organic vapour can attach to the $A_{2} T_{2}$ clusters and promote further growth.

The high concentration of an organic vapour attaching to the $\mathrm{A}_{2} \mathrm{~B}_{2}$-clusters increases the values of the coefficients $K_{\mathrm{A} 2 \mathrm{~T} 2}$ and $K_{\mathrm{A} 2 \mathrm{D} 1 \mathrm{~T} 1}$ by two mechanisms. First, in Fig. 7 the value of $K_{\mathrm{A} 2 \mathrm{~T} 2}$ does not change when $\left[\mathrm{A}_{1, \text { tot }}\right]$ increases from $10^{6}$ to $10^{7} \mathrm{~cm}^{-3}$, whereas in the absence of the organic vapour a similar change in $\left[\mathrm{A}_{1, \text { tot }}\right]$ increased the value of $K_{\mathrm{A} 2 \mathrm{~T} 2}$ by over an order of magnitude (blue solid lines in Fig. 5a-c). As explained in Sect. 3.3.1, the reason for the increase in the values of $K_{\mathrm{A} 2 \mathrm{~T} 2}$ with [ $\mathrm{A}_{1, \text { tot }}$ ] was the increasing probability of $\mathrm{A}_{2} \mathrm{~B}_{2}$-clusters to grow before evaporation. In the case where abundant organic vapour is mainly responsible for the growth of the $\mathrm{A}_{2} \mathrm{~B}_{2}$-clusters, this probability and thus also the values of the related coefficients $K_{\mathrm{A} 2 \mathrm{~T} 2}$ become independent of $\left[\mathrm{A}_{1, \text { tot }}\right]$ (elevated values of $K_{\mathrm{A} 2 \mathrm{~T} 2}$ at high temperatures and $\left[\mathrm{A}_{1, \text { tot }}\right]=10^{8} \mathrm{~cm}^{-3}$ seem to result, at least partly, from the limitations of our model, see Sects. 3.3.1 and 5.1). A second mechanism affecting the values of $K_{\mathrm{A} 2 \mathrm{~T} 2}$ and $K_{\mathrm{A} 2 \mathrm{D} 1 \mathrm{~T} 1}$ is the diminished impact of the conversion of $\mathrm{A}_{2} \mathrm{~T}_{2}$ clusters to $A_{2} D_{1} T_{1}$ - and further to $A_{2} D_{2}$-clusters. This effect becomes less significant as the $\mathrm{A}_{2} \mathrm{~T}_{2}$ - and $\mathrm{A}_{2} \mathrm{D}_{1} \mathrm{~T}_{1}$-clusters collide more often with an organic vapour molecule than with a DMA molecule. At amine concentrations equal to the applied organic vapour concentration, $10^{9} \mathrm{~cm}^{-3}$, this effect decreases the value of $K_{\mathrm{A} 2 \mathrm{~T} 2}$. The impact of organic vapour

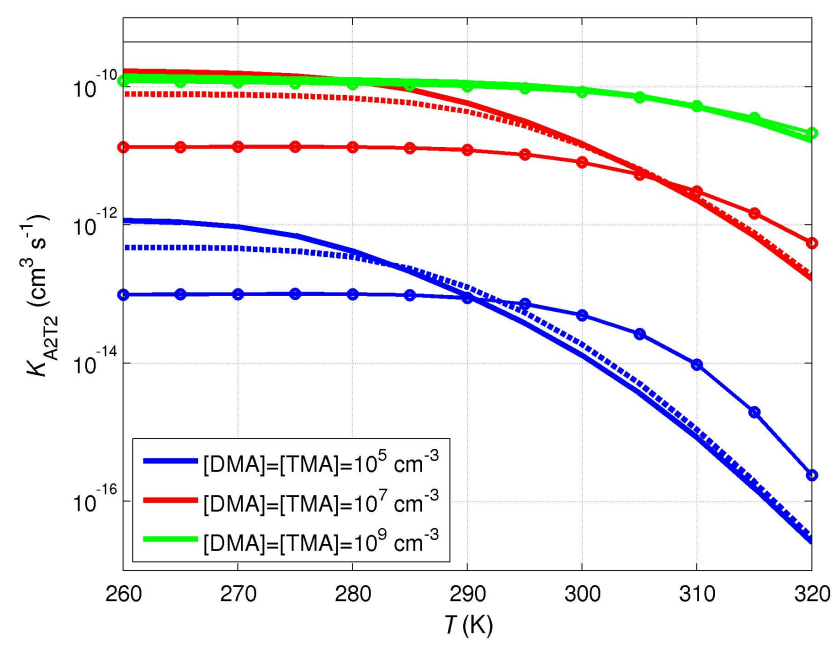

Fig. 7. The modelled coefficient $K_{\mathrm{A} 2 \mathrm{~T} 2}$ as a function of temperature assuming that the $\mathrm{A}_{2} \mathrm{~T}_{2}$ and $\mathrm{A}_{2} \mathrm{D}_{1} \mathrm{~T}_{1}$-clusters are grown out of the model when colliding with organic vapour molecules at concentration of $10^{9} \mathrm{~cm}^{-3}$. The solid lines correspond to total $\mathrm{H}_{2} \mathrm{SO}_{4}$ monomer concentration $\left[\mathrm{A}_{1, \text { tot }}\right]=10^{6} \mathrm{~cm}^{-3}$, the dashed to $\left[\mathrm{A}_{1, \text { tot }}\right]$ $=10^{7} \mathrm{~cm}^{-3}$ and the solid lines with circles to $\left[\mathrm{A}_{1, \mathrm{tot}}\right]=10^{8} \mathrm{~cm}^{-3}$.

collisions on the values of the coefficient $K_{\mathrm{A} 2 \mathrm{D} 1 \mathrm{~T} 1}$ is similar to the above described effect on $K_{\mathrm{A} 2 \mathrm{~T} 2}$.

\section{Comparison of model results with atmospheric observations}

When interpreting the comparison of model results and ambient data, it should be kept in mind that the formation rate of $2 \mathrm{~nm}$ particles (or $1.5 \mathrm{~nm}$ particles in case of Hyytiälä 2003 and 2005 data) is somewhat lower than the initial particle formation rate. This is due to the coagulational losses during the growth of particles up to $2 \mathrm{~nm}$ (e.g. Kerminen and Kulmala, 2002). The diameter of the $\mathrm{A}_{2} \mathrm{~B}_{2}$-clusters comparable to the electrical mobility diameters applied in the ambient data would be roughly $1.2 \mathrm{~nm}$ (Ehn et al., 2011).

The measured atmospheric formation rate of $2 \mathrm{~nm}$ particles $\left(J_{2 \mathrm{~nm}}\right)$ is depicted in Fig. 8a as a function of the sulphuric acid monomer collision rate. The particle formation rate $J_{2 \mathrm{~nm}}$ is in line with the squared sulphuric acid concentration especially when the data sets are examined separately. However, the values of the coefficient $K_{\text {obs }}$ (see Eq. 2) vary substantially between the sites and are much lower than the actual collision rate of two $\mathrm{H}_{2} \mathrm{SO}_{4}$ monomers, with a median value of $K_{\mathrm{obs}}=1.4 \times 10^{-13} \mathrm{~cm}^{3} \mathrm{~s}^{-1}$.

In Fig. 8b we show the values of $K_{\text {obs }}$ as a function of temperature. In addition to the observed values of the coefficient $K_{\text {obs }}$, the values of the modelled coefficients $K_{\mathrm{A} 2 \mathrm{D} 2}$ and $K_{\mathrm{A} 2 \mathrm{~T} 2}$ at low amine concentrations are depicted for comparison. We do not present separately the comparison between $K_{\mathrm{obs}}$ and the sum of all coefficients $K_{\mathrm{A} 2 \mathrm{~B} 2}$, because 

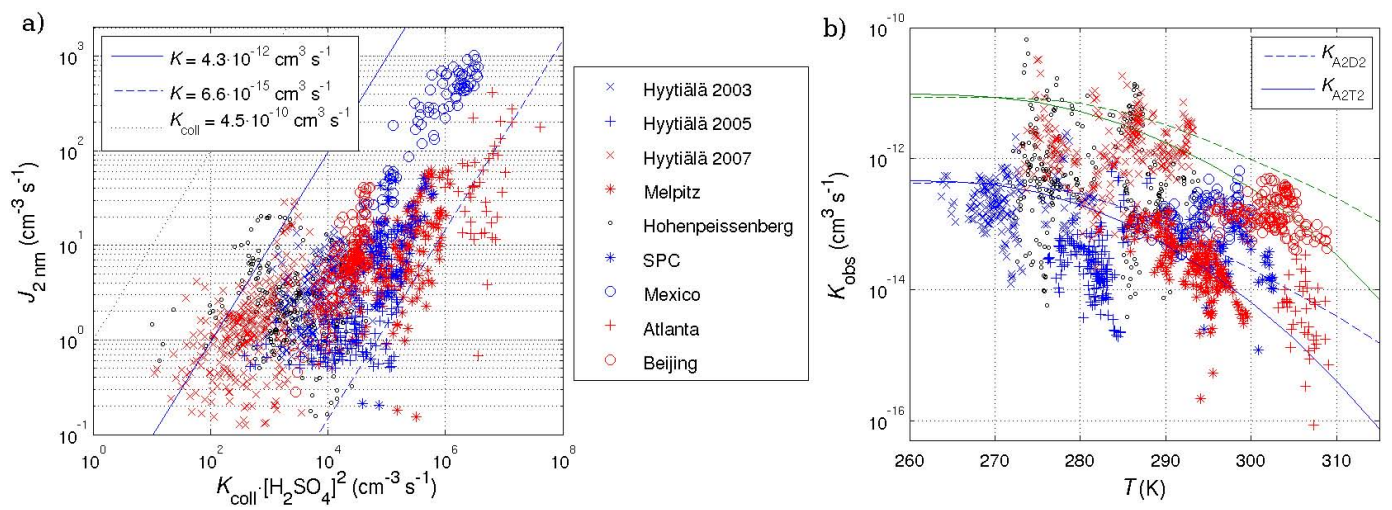

Fig. 8. (a) The measured formation rate of $2 \mathrm{~nm}$ particles $\left(J_{2 \mathrm{~nm}}\right)$ as a function of sulphuric acid monomer collision rate. The solid and dashed lines correspond to the 95 th and 5 th percentile of the data point specific values of $J /\left(K_{\mathrm{coll}} \cdot\left[\mathrm{H}_{2} \mathrm{SO}_{4}\right]^{2}\right)$, respectively, leaving $90 \%$ of the data points between the lines. The collision rate between sulphuric acid monomers is depicted with a dotted line. Panel (b) shows the observed coefficient $K_{\mathrm{obs}}$ as a function of temperature. The solid and dashed lines correspond to the values of the modelled coefficients $K_{\mathrm{A} 2 \mathrm{D} 2}$ and $K_{\mathrm{A} 2 \mathrm{~T} 2}$, respectively, at amine concentrations of $10^{5} \mathrm{~cm}^{-3}$ (blue lines) and $10^{6} \mathrm{~cm}^{-3}$ (green lines), $\mathrm{RH}=50 \%$ and $\left[\mathrm{A}_{1, \text { tot }}\right]=10^{7} \mathrm{~cm}-3$.

this sum differs significantly from $K_{\mathrm{A} 2 \mathrm{D} 2}$ only in case of $1: 10$ ratio of [DMA] and [TMA], in which case it is practically equal to $K_{\mathrm{A} 2 \mathrm{~T} 2}$. The atmospheric data set shows, as a whole, quite a gentle decrease of $K_{\text {obs }}$ with increasing temperature, even gentler than that of the modelled coefficient $K_{\mathrm{A} 2 \mathrm{D} 2}$ (least squares fittings to the values of $K_{\mathrm{obs}}, K_{\mathrm{A} 2 \mathrm{D} 2}$ and $K_{\mathrm{A} 2 \mathrm{~T} 2}$ at the observed temperatures with $T>280 \mathrm{~K}$ (or $290 \mathrm{~K})$ result in exponential dependencies $K_{i} \sim \exp \left(\alpha_{i} \cdot T\right)$ with $\alpha_{\text {obs }}=-0.08 \mathrm{~K}^{-1}\left(-0.09 \mathrm{~K}^{-1}\right), \alpha_{\mathrm{A} 2 \mathrm{D} 2}=-0.12 \mathrm{~K}^{-1}$ $\left(-0.14 \mathrm{~K}^{-1}\right)$ and $\left.\alpha_{\mathrm{A} 2 \mathrm{~T} 2}=-0.17 \mathrm{~K}^{-1}\left(-0.20 \mathrm{~K}^{-1}\right)\right)$. However, steeper decreases of $K_{\mathrm{obs}}$, closer to that of $K_{\mathrm{A} 2 \mathrm{~T} 2}$ and $K_{\mathrm{A} 2 \mathrm{D} 1 \mathrm{~T} 1}$, can be seen quite clearly in the Melpitz and SPC data, but also in the Beijing and Hyytiälä 2005 data sets. This kind of behaviour might follow from particle formation related to formation of $\mathrm{A}_{2} \mathrm{~T}_{2}$ or $\mathrm{A}_{2} \mathrm{D}_{1} \mathrm{~T}_{1}$-clusters, if the amine concentrations were roughly connected to long term mean temperatures. These estimations of the slope are, however, not to be taken as a profound inspection of the behaviour of the ambient data. A more detailed analysis remains for future studies.

Due to the large number of atmospheric data points, we did not make separate model runs matching the atmospheric conditions of each data point. Instead, we ran the model within ranges that cover all the ambient measurements with representative intervals for each quantity - at temperatures from 260 to $310 \mathrm{~K}$ in $5 \mathrm{~K}$ intervals, at RHs from 0 to $85 \%$ in $5 \%$ intervals and at total sulphuric acid monomer concentrations from $10^{5}$ to $3.2 \times 10^{8} \mathrm{~cm}^{-3}$ with intervals of a factor 3.16 (i.e. $\left.10^{5}, 3.16 \times 10^{5}, 10^{6}, \ldots \mathrm{cm}^{-3}\right)$. The model runs were conducted with [DMA] to [TMA] ratios $1: 1,1: 10$ and $10: 1$, both in absence and presence of an organic vapour with concentration $10^{9} \mathrm{~cm}^{-3}$ adhering to $\mathrm{A}_{2} \mathrm{~B}_{2}$-clusters. From these values of modelled coefficients $K_{\mathrm{A} 2 \mathrm{~B} 2}$ we interpolated coefficients $K_{\mathrm{A} 2 \mathrm{~B} 2}\left(T, \mathrm{RH},\left[\mathrm{A}_{1, \text { tot }}\right]\right)$ for the conditions of each ambient measurement. The interpolation was made separately for the values of $K_{\mathrm{A} 2 \mathrm{D} 2}, K_{\mathrm{A} 2 \mathrm{~T} 2}$ and $K_{\mathrm{A} 2 \mathrm{D} 1 \mathrm{~T} 1}$ resulting from the different model runs, with amine concentrations set to a constant value of $10^{6} \mathrm{~cm}^{-3}$.

We first compared the variability of the data pointspecific ratio $K_{\mathrm{obs}} / K_{\mathrm{A} 2 \mathrm{~B} 2}\left(T, \mathrm{RH},\left[\mathrm{A}_{1, \text { tot }}\right]\right)$ between the different model runs. The corresponding variability in Fig. 8a, determined as the ratio of the 95th to 5 th percentile of $K_{\text {obs }} / K_{\text {coll }}$, is $4.3 \times 10^{-12} / 6.6 \times 10^{-15}=650$. This variation decreased when any of the modelled coefficients $K_{\mathrm{A} 2 \mathrm{~B} 2}$ was applied instead of constant $K_{\text {coll }}$, except when the values of $K_{\mathrm{A} 2 \mathrm{~T} 2}$ or $K_{\mathrm{A} 2 \mathrm{D} 1 \mathrm{~T} 1}$ from the model runs without organic vapours were used. In the latter cases the variation factor increased because the formation rates $J_{\mathrm{A} 2 \mathrm{~T} 2}$ and $J_{\mathrm{A} 2 \mathrm{D} 1 \mathrm{~T} 1}$ related to these model runs are associated with a cubed sulphuric acid concentration at $T>290 \mathrm{~K}$, which is not observed in the atmospheric data. The smallest value for the variability, 130 , resulted from the modelled $K_{\mathrm{A} 2 \mathrm{D} 2}$ with a [DMA] to [TMA] ratio $1: 10$ in the absence of organic vapours. The smallest variabilities related to the modelled coefficients $K_{\mathrm{A} 2 \mathrm{~T} 2}$ or $K_{\mathrm{A} 2 \mathrm{D} 1 \mathrm{~T} 1}$ (360 and 280 , respectively) were obtained with a [DMA] to [TMA]-ratio of $10: 1$ in the presence of organic vapours growing the $\mathrm{A}_{2} \mathrm{~B}_{2}$-clusters. The smaller variabilities between the observed and modelled formation rates being related to $K_{\mathrm{A} 2 \mathrm{D} 2}$ than those related to coefficients $K_{\mathrm{A} 2 \mathrm{~T} 2}$ or $K_{\mathrm{A} 2 \mathrm{D} 1 \mathrm{~T} 1}$ in presence of organic vapours may result from the assumed constant amine concentration: as the overall temperature dependence of $K_{\mathrm{obs}}$ is closer to that of $K_{\mathrm{A} 2 \mathrm{D} 2}$ (Fig. 8b), the smallest overall variability is also achieved with this coefficient. However, this analysis shows that the formation rates of $A_{2} T_{2}$ - or $A_{2} D_{1} T_{1}$-clusters fail to reproduce the measured particle formation rates if organic vapours are not let to adhere to these clusters.

Even though the strongest impact on the modelled coefficients $K_{\mathrm{A} 2 \mathrm{~B} 2}$ is that of temperature, the different $\mathrm{RH}$ dependencies of $K_{\mathrm{A} 2 \mathrm{D} 2}, K_{\mathrm{A} 2 \mathrm{~T} 2}$ and $K_{\mathrm{A} 2 \mathrm{D} 1 \mathrm{~T} 1}$ (see Fig. 6) can 
provide a clue to which mechanism is closest to the atmospheric observations. To study the RH dependence of the observed coefficient $K_{\text {obs }}$, we first need to take into account the marked impact of the temperature on both $K_{\mathrm{obs}}$ and $\mathrm{RH}$. This was made by scaling the values of the coefficient $K_{\text {obs }}$ to the same temperature with the temperature dependence of the modelled coefficients $K_{\mathrm{A} 2 \mathrm{~B} 2}$. This scaling is functionally equivalent to moving all the data points in Fig. $8 \mathrm{~b}$ to the same temperature by following the model lines, but now including the impact of varying concentrations $\left[\mathrm{A}_{1, \text { tot }}\right]$ on the temperature dependencies of $K_{\mathrm{A} 2 \mathrm{~B} 2}$ (see Fig. 4). The numerical comparison of the correlations between $\mathrm{RH}$ and the values of the observed coefficients $K_{\text {obs }}$ at the measured temperature, as well as those with the temperature scaled to $300 \mathrm{~K}$ $\left(K_{300}\right)$ are presented in Table 3 for all the sites separately. The logarithmic value of $K_{300}$ correlates negatively with RH at all the measurement sites except Hohenpeissenberg and Atlanta. However, at Atlanta, as well as at Melpitz, the correlation is not significant ( $\mathrm{p}$-value $>>10^{-5}$ ). The values of $\beta$ in $K_{300}=\alpha \cdot \exp (\beta \cdot \mathrm{RH})$ from the linear regression fits to the $K_{300}$ values interpolated with $K_{\mathrm{A} 2 \mathrm{~T} 2}$ with organic vapours were in the range of -12 to -2.7 at all sites with a significant correlation except for Hohenpeissenberg. Similar values were achieved with other $K_{\mathrm{A} 2 \mathrm{~B} 2 \text {-coefficients used for }}$ interpolation, as well. The linear regression fits to the RHdependencies of $K_{\mathrm{A} 2 \mathrm{D} 2}, K_{\mathrm{A} 2 \mathrm{~T} 2}$ and $K_{\mathrm{A} 2 \mathrm{D} 1 \mathrm{~T} 1}$ (see Fig. 6) result in $\beta$-values of $0.033,-1.6$ and -0.68 , respectively. Thus, the observed RH dependence suggests that the atmospheric particle formation rate is better associated with the formation rate of $\mathrm{A}_{2} \mathrm{~T}_{2}$-clusters than with the formation rate of $\mathrm{A}_{2} \mathrm{D}_{2}$-clusters.

\section{Discussion}

\subsection{On the stability of clusters with three or more acids}

We investigated the formation rate of $A_{2} B_{2}$-clusters with the assumption that the $\mathrm{A}_{2} \mathrm{~B}_{2}$-clusters with DMA or/and TMA are capable of growing further when colliding with sulphuric acid monomers. Ortega et al. (2012) have presented theoretical evidence that this is the case concerning the DMAclusters, but the growth ability of $\mathrm{A}_{2} \mathrm{~T}_{2}$-clusters is not selfevident. This doubt arises from the fact that the three methyl groups in the TMA-molecule leave room for the nitrogen atom to make only one hydrogen bond, whereas the nitrogen in DMA can make two hydrogen bonds. Thus, the TMA molecules themselves are not capable of binding the third sulphuric acid (or other vapour molecule) to the $A_{2} T_{2}$ cluster, but it could attach to the cluster by bonding to the sulphuric acid molecules. On the other hand, the high stability of the $\mathrm{A}_{2} \mathrm{~T}_{1}$-cluster, in which one other sulphuric acid molecule is not bound directly to the TMA, shows that also the bond between two sulphuric acids in a base-stabilized cluster can be very strong. In addition, some experimental studies have shown that increasing [TMA] increases the particle formation rate (Erupe et al., 2011; Yu et al., 2012).

In the discussion related to Figs. 4 and 7 we pointed out that the values of all coefficients $K_{\mathrm{A} 2 \mathrm{~B} 2}$ increase with the total sulphuric acid monomer concentration, $\left[\mathrm{A}_{1, \text { tot }}\right]$, at high temperatures when $\left[\mathrm{A}_{1, \text { tot }}\right]$ is orders of magnitude larger than the amine concentration. This feature originates from the increasing concentrations of $\mathrm{A}_{2} \mathrm{~B}_{1}$-clusters, which under the given conditions exceeds the concentrations of gas phase amines, and thus the collisions between two $\mathrm{A}_{2} \mathrm{~B}_{1}$-clusters contributes significantly to the positive terms in $J_{\mathrm{A} 2 \mathrm{~B} 2}$ (see Eq. 13). Since the applied cluster energy calculations do not cover the resulting $\mathrm{A}_{4} \mathrm{~B}_{2}$-cluster, the negative terms describing the reverse evaporation are not affected. Ortega et al., (2012) showed that $A_{4} D_{2}$-clusters evaporate $A_{2} D_{1}$-cluster (thus forming two $\mathrm{A}_{2} \mathrm{D}_{1}$-clusters) at relatively high rate (3 $\mathrm{s}^{-1}$ at $\left.298.16 \mathrm{~K}\right)$. Thus, it seems that the above discussed increase in the values of $K_{\mathrm{A} 2 \mathrm{~B} 2}$ would be less pronounced than that seen in Figs. 4, 5 and 7, if the evaporation rates for larger clusters were taken into account. The evaporations of other $\mathrm{A}_{\leq 4} \mathrm{D}_{\leq 4}$ clusters resulting in clusters smaller than $\mathrm{A}_{2} \mathrm{D}_{2}$ are slow $\left(<5 \times 10^{-3} \mathrm{~s}^{-1}\right.$ at $298.16 \mathrm{~K}$, Ortega et al., 2012). Since $\mathrm{A}_{4} \mathrm{~B}_{2}$-clusters are formed efficiently only when $\left[\mathrm{A}_{1, \text { tot }}\right]$ is orders of magnitude higher than $[\mathrm{B}]$, we may assume that at other conditions the evaporations of the $\mathrm{A}_{>2} \mathrm{D}_{\geq 2}$-clusters do not have marked effect on the formation rate $J_{\mathrm{A} 2 \mathrm{D} 2}$. However, the effects of the corresponding evaporations on $J_{\mathrm{A} 2 \mathrm{~T} 2}$ and $J_{\mathrm{A} 2 \mathrm{D} 1 \mathrm{~T} 1}$ remain to be evaluated by further studies.

\subsection{On the comparison to ambient data}

We showed that the formation rates $J_{\mathrm{A} 2 \mathrm{~B} 2}$ are not always coupled with the sulphuric acid concentration to the power of exactly two, but the exponent varies from below two to greater than three. Values below two are related to the situation in which the amine and sulphuric acid monomer concentrations are of the same order of magnitude. In this case e.g. increasing the sulphuric acid concentration with constant amine concentration decreases the proportion of sulphuric acid monomers being clustered with amines, and consequently the formation rate of $\mathrm{A}_{2} \mathrm{~B}_{2}$-clusters per sulphuric acid monomer collisions decreases. The exponent values below two were found only for temperatures below $300 \mathrm{~K}$. Exponent values larger than two are possible for the formation rate $J_{\mathrm{A} 2 \mathrm{D} 2}$ only when $\left[\mathrm{A}_{1, \text { tot }}\right]$ exceeds the amine concentration by more than two orders of magnitude and the temperature is over $290 \mathrm{~K}$. The formation rates $J_{\mathrm{A} 2 \mathrm{~T} 2}$ and $J_{\mathrm{A} 2 \mathrm{D} 1 \mathrm{~T} 1}$, instead, are associated with close to cubed sulphuric acid concentrations when $A_{1, \text { tot }}$ are the most abundant or only vapours/clusters able to promote further growth of $\mathrm{A}_{2} \mathrm{~T}_{2}$ - and $A_{2} D_{1} T_{1}$-clusters. If an organic vapour is present in equal or higher concentrations than that of sulphuric acid and can attach to the $\mathrm{A}_{2} \mathrm{~B}_{2}$-clusters, the exponent values of three are not encountered. Intriguingly, the range in which the exponent varies agrees with the atmospheric observations of 
Table 3. Numerical comparison of the RH dependencies of the observed coefficients $K$ at the measured temperature $\left(K=K_{\mathrm{obs}}\right)$ and when $K_{\text {obs }}$ is scaled to $T=300 \mathrm{~K}\left(K=K_{300}\right)$. Presented values are the correlation coefficient $R$, the p-value describing the probability of coincidental correlation of this strength, and the value of $\beta$ in $K=\alpha \cdot \exp (\beta \cdot \mathrm{RH})$ from linear regression fits. The compared values of $K_{300}$ are scaled to $300 \mathrm{~K}$ with the temperature dependence of coefficient $K_{\mathrm{A} 2 \mathrm{~T} 2}$ from the model run with organic vapours, but the correlations were similar when scaling was done with the temperature dependence of any of the coefficients $K_{\mathrm{A} 2 \mathrm{D} 2}, K_{\mathrm{A} 2 \mathrm{~T} 2}$ or $K_{\mathrm{A} 2 \mathrm{D} 1 \mathrm{~T} 1}$.

\begin{tabular}{lrrr|rrr}
\hline Site/Campaign & \multicolumn{3}{c|}{$K=K_{\text {obs }}$} & \multicolumn{3}{c}{$K=K_{300}$} \\
\cline { 2 - 6 } & $\begin{array}{r}R(\mathrm{RH}, \\
\log (K))\end{array}$ & $\begin{array}{r}p(\mathrm{RH}, \\
\log (K))\end{array}$ & $\begin{array}{r}\text { Fitted } \beta \text { in } \\
K \sim e^{\beta \cdot \mathrm{RH} / 100}\end{array}$ & $\begin{array}{r}R(\mathrm{RH}, \\
\log (K))\end{array}$ & $\begin{array}{r}p(\mathrm{RH}, \\
\log (K))\end{array}$ & $\begin{array}{r}\text { Fitted } \beta \text { in } \\
\beta \cdot \mathrm{RH} / 100\end{array}$ \\
\hline Hyytiälä 2003 & -0.16 & $3 \times 10^{-2}$ & -1.4 & -0.31 & $2 \times 10^{-5}$ & -2.7 \\
Hyytiälä 2005 & -0.24 & $3 \times 10^{-3}$ & -3.2 & -0.36 & $3 \times 10^{-6}$ & -4.7 \\
Hyytiälä 2007 & -0.53 & $3 \times 10^{-21}$ & -6.7 & -0.74 & $6 \times 10^{-48}$ & -12 \\
Melpitz & 0.27 & $1 \times 10^{-4}$ & 4.3 & -0.04 & $6 \times 10^{-1}$ & -0.44 \\
Hohenpeissenberg & 0.49 & $2 \times 10^{-18}$ & 5.8 & 0.40 & $9 \times 10^{-13}$ & 4.5 \\
S. P. Capofiume & -0.14 & $3 \times 10^{-1}$ & -1.2 & -0.49 & $5 \times 10^{-5}$ & -4.4 \\
Mexico City & -0.42 & $1 \times 10^{-5}$ & -1.7 & -0.69 & $1 \times 10^{-15}$ & -4.1 \\
Atlanta & 0.34 & $2 \times 10^{-2}$ & 6.8 & 0.20 & $2 \times 10^{-1}$ & 4.0 \\
Beijing & 0.03 & $7 \times 10^{-1}$ & 0.15 & -0.39 & $5 \times 10^{-7}$ & -3.3 \\
ALL SITES & -0.16 & $2 \times 10^{-10}$ & -2.5 & -0.30 & $1 \times 10^{-31}$ & -4.4 \\
\hline
\end{tabular}

the association between particle formation rate and sulphuric acid concentration, as the exponents basing on observations are typically from one to two, and in some cases even three. However, the exponents of the initial and observed particle formation rates are not necessarily the same, but they may change during the growth to the size of the observed particles (Korhonen et al., 2011).

Our model runs were made with three different [DMA] to [TMA] ratios, $1: 1,10: 1$ and $1: 10$. These ratios cover mostly the measured ratios at sites varying from rural to agricultural and urban areas (Ge et al., 2011). However, it should be noted that the measured DMA and TMA concentrations do not necessarily describe only the free molecular concentrations, but e.g. the amine molecules clustered with some acids might also be accounted. This is a similar problem to the consideration of whether the CIMS detects the $\mathrm{A}_{1} \mathrm{~B}_{1}$-clusters or not, discussed in Sect. 2.1.2. Furthermore, in the atmosphere a wide variety of different amines exists, and other amines can also play a role in the cluster formation process. In particular, monomethylamine and some ethylamines have been reported to have concentrations comparable to those of DMA and TMA (Ge et al., 2011). They could have a significant effect on particle formation - those with more alkyl-groups due to their strong basicity, and e.g. monomethylamine due to its ability to form up to three hydrogen bonds and thus possibly facilitate the formation of larger sulphuric acid-amine-clusters together with other more basic amines.

The steepness of the decreasing values of $K_{\mathrm{A} 2 \mathrm{~T} 2}$ and $K_{\mathrm{A} 2 \mathrm{D} 1 \mathrm{~T} 1}$ with temperature results from two cluster types, $A_{1} B_{1}$ and $A_{2} B_{2}$, with evaporation rates that strongly affect the formation rate of $A_{2} T_{2}$ - and $A_{2} D_{1} T_{1}$-clusters. The apparent similarity in the decrease of the observed coefficient
$K_{\text {obs }}$ may suggest that on the way from gas phase molecules to a growing particle the number of clusters with evaporation rates that effectively decrease the particle formation rate is precisely two, regardless of the nature of the actual particle formation mechanism. If there were only one cluster whose concentration was remarkably affected by the evaporation, the decrease would be gentler, similar to that of $J_{\mathrm{A} 2 \mathrm{D} 2}$, and if there were three or more clusters whose concentration decreased exponentially with temperature, the decrease in particle formation rate would be steeper. Furthermore, it seems that the larger of the two clusters, which are strongly affected by the evaporation rate, needs to be able to grow in collisions with other and more abundant vapours than sulphuric acid: otherwise the observed particle formation rate would be associated with the sulphuric acid concentration to the power three rather than two.

With the observed temperature and $\mathrm{RH}$ dependencies, the atmospheric particle formation rate $J$ seems to be better associated with the modelled formation rates $J_{\mathrm{A} 2 \mathrm{~T} 2}$ and $J_{\mathrm{A} 2 \mathrm{D} 1 \mathrm{~T} 1}$ than with $J_{\mathrm{A} 2 \mathrm{D} 2}$. However, in order to obtain similar behaviour for coefficients $K_{\mathrm{A} 2 \mathrm{~T} 2}$ and $K_{\mathrm{A} 2 \mathrm{D} 1 \mathrm{~T} 1}$ to that of $K_{\text {obs }}$, it is required that the organic vapours are capable of condensing on these $\mathrm{A}_{2} \mathrm{~B}_{2}$-clusters. It is possible that the bonding of organic molecules to clusters of sulfuric acid with TMA (or other tertiary amines) could be slightly enhanced by interactions between nonpolar alkyl groups of the amines and the condensing organics. This could at least partially compensate for the smaller number of hydrogen bonds formed per amine.

Regardless the similar trends in the temperature and $\mathrm{RH}$ dependencies of the observed coefficient $K_{\text {obs }}$ and the modelled coefficients $K_{\mathrm{A} 2 \mathrm{~T} 2}$ and $K_{\mathrm{A} 2 \mathrm{D} 1 \mathrm{~T} 1}$, the atmospheric observations as whole showed milder temperature dependence. 
This kind of behaviour could arise, among other reasons, from a positive correlation between temperature and amine emissions. Because amines are efficiently emitted from soil and oceans (Ge et al., 2011), most probably in relation to biological processes, this type of temperature dependence can be expected. This possible association reflects the complexity of determining the impact of temperature on atmospheric particle formation. There are several processes which may elevate the observed particle formation rate when temperature increases: in addition to decreasing humidity and presumably increasing amine concentration, increasing temperature elevates the emissions of volatile organic compounds (Gunther et al., 1995) which after oxidation grow the freshly formed particles (e.g. Riipinen et al., 2011). Thus, even if the particle formation rate did not increase with temperature, at least the proportion of formed particles surviving to $2 \mathrm{~nm}$ size does. With all these factors altering the observed particle formation rate at higher temperatures, the suppressing effect of temperature itself must be quite strong to result in negative correlation between the temperature and the coefficient $K_{\text {obs }}$.

\section{Summary and conclusions}

We modelled the formation rate of clusters consisting of two sulphuric acid and two amine molecules with a kinetic cluster model (DACM). These clusters are necessary intermediates in the formation of larger sulphuric acid-amine-clusters. If atmospheric particle formation is a phenomenon related to formation of acid-base-clusters, it seems evident that the atmospheric particle formation rate should not exceed the formation rate of these clusters. We applied quantum chemical calculations for determining the evaporation rates for the clusters of sulphuric acid (A), trimethylamine (T) and dimethylamine (D) in a temperature range from $260 \mathrm{~K}$ to $320 \mathrm{~K}$, and studied the formation rates $J_{\mathrm{A} 2 \mathrm{~B} 2}$ of $\mathrm{A}_{2} \mathrm{~T}_{2-}, \mathrm{A}_{2} \mathrm{D}_{2}$ - and $\mathrm{A}_{2} \mathrm{D}_{1} \mathrm{~T}_{1}$-clusters.

Our purpose was to perform the modelling with input parameters as close to atmospheric experimental circumstances as possible. As recent experimental (Petäjä et al., 2011) and theoretical (Kurtén et al., 2011) studies have suggested, the state-of-the-art instrument for measuring sulphuric acid concentration, Chemical Ionization Mass Spectrometer (CIMS), detects the main fraction of $A_{1} D_{1}$-clusters as pure sulphuric acid. We assumed that the same holds for $\mathrm{A}_{1} \mathrm{~T}_{1}$-clusters, and thus compared the formation rates $J_{\mathrm{A} 2 \mathrm{~B} 2}$ with the total concentration of the sulphuric acid monomers, $\left[\mathrm{A}_{1, \text { tot }}\right]$, calculated as a sum of the concentrations of $A, A_{1} D_{1}$ and $A_{1} T_{1}$. We ran the model with $A_{1, \text { tot }}$ and amine concentrations from $10^{5}$ to $10^{9} \mathrm{~cm}^{-3}$, which likely covers the typical atmospheric conditions, even though direct measurements of the gas phase amine concentrations are currently not available. The effect of meteorological conditions and vapours participating to particle formation was studied by examining the behaviour of coefficients $K_{\mathrm{A} 2 \mathrm{~B} 2}$ in $J_{\mathrm{A} 2 \mathrm{~B} 2}=K_{\mathrm{A} 2 \mathrm{~B} 2} \cdot\left[\mathrm{A}_{1, \text { tot }}\right]^{2}$ as functions of temperature, $\mathrm{RH}$ and vapour concentrations.

We found that the coefficients $K_{\mathrm{A} 2 \mathrm{~B} 2}$ are dependent on the amine and sulphuric acid concentration, on the ratios between these concentrations and of the amine concentrations with each other, as well as on temperature and RH. In the case where the amine concentration is an order of magnitude higher than $\left[\mathrm{A}_{1, \text { tot }}\right]$ and the temperature is below $270 \mathrm{~K}$, a large enough fraction of sulphuric acid molecules is clustered with the amines to result in a formation rate close to the collision rate of $A_{1, \text { tot }}$. Close to collision rate values for $J_{\mathrm{A} 2 \mathrm{~B} 2}$ were also found at higher temperatures, up to $300 \mathrm{~K}$, under high amine concentrations $\left(>10^{8} \mathrm{~cm}^{-3}\right)$.

The temperature dependence of the coefficients $K_{\mathrm{A} 2 \mathrm{~B} 2}$ arising from the exponential increase of the cluster evaporation rates as functions of temperature, was found to be very strong. The value of the coefficient $K_{\mathrm{A} 2 \mathrm{D} 2}$ decreased by roughly an order of magnitude for an increase of $15 \mathrm{~K}$ in temperature, because of the increasing evaporation rate from the $\mathrm{A}_{1} \mathrm{D}_{1}$-cluster. A similar temperature change decreased the values of the coefficients $K_{\mathrm{A} 2 \mathrm{~T} 2}$ and $K_{\mathrm{A} 2 \mathrm{D} 1 \mathrm{~T} 1}$ by two orders of magnitude, because in addition to evaporation of $A_{1} D_{1}$ - or $A_{1} T_{1}$-clusters the evaporation rates from $A_{2} T_{2}$ and $\mathrm{A}_{2} \mathrm{D}_{2} \mathrm{~T}_{1}$-clusters limited the formation rate. The exponential decrease of the coefficients $K_{\mathrm{A} 2 \mathrm{~B} 2}$ started in temperatures between 260 and $310 \mathrm{~K}$. The lowest on-set temperatures for the decrease were related to low atmospheric sulphuric acid concentrations $\left(\sim 10^{6} \mathrm{~cm}^{-3}\right)$ together with similar or lower amine concentrations, and the on-set temperature increased with increasing $\left[\mathrm{A}_{1, \text { tot }}\right]$ and when the amine concentration was orders of magnitude higher than $\left[\mathrm{A}_{1, \text { tot }}\right]$. In addition to temperature, the relative humidity had an impact on the formation rates $J_{\mathrm{A} 2 \mathrm{~B} 2}$. The values of the coefficients $K_{\mathrm{A} 2 \mathrm{~T} 2}$ and $K_{\mathrm{A} 2 \mathrm{D} 1 \mathrm{~T} 1}$ decreased with an increasing $\mathrm{RH}$, whereas $K_{\mathrm{A} 2 \mathrm{D} 2}$ was not significantly affected by RH. This effect was less pronounced than that of temperature: the steepest decrease was obtained for $K_{\mathrm{A} 2 \mathrm{~T} 2}$ which decreased roughly by a factor two when RH increases by $20 \%$-units.

In addition to the influence of meteorological parameters and amine concentration (or the proportion of amine concentration to sulphuric acid concentration), we found that the values of $K_{\mathrm{A} 2 \mathrm{~B} 2}$ are affected directly by the concentration of sulphuric acid. Thus the formation rates $J_{\mathrm{A} 2 \mathrm{~B} 2}$ are not always associated with sulphuric acid concentration to power of two exactly, but at low atmospherically relevant temperatures the value of the exponent decreases from two. Even more intriguingly, at high atmospherically relevant temperatures the formation rates $J_{\mathrm{A} 2 \mathrm{~T} 2}$ and $J_{\mathrm{A} 2 \mathrm{D} 1 \mathrm{~T} 1}$ turned out to be associated with sulphuric acid to the power of three, if the sulphuric acid is the only or the main compound growing the $\mathrm{A}_{2} \mathrm{~B}_{2}$-clusters further. Such power law dependencies with exponents higher than two have been reported, e.g. during the hot season in Beijing (Wang et al., 2011).

Finally we made a comparison between the modelled coefficients $K_{\mathrm{A} 2 \mathrm{~B} 2}$ and the coefficients $K_{\mathrm{obs}}$ determined from 
the measurements of particle formation rates and sulphuric acid concentrations conducted in diverse atmospheric conditions. When $K_{\text {obs }}$ is plotted against temperature, the overall figure has a similar decreasing trend with temperature as that of $K_{\mathrm{A} 2 \mathrm{D} 2}$. However, at several sites the coefficient $K_{\mathrm{obs}}$ exhibited a steeper decrease with increasing temperature, similar to those of the modelled coefficients $K_{\mathrm{A} 2 \mathrm{~T} 2}$ and $K_{\mathrm{A} 2 \mathrm{D} 1 \mathrm{~T} 1}$. Furthermore, the coefficient $K_{\text {obs }}$ showed a similar decreasing trend with increasing $\mathrm{RH}$ to the coefficient $K_{\mathrm{A} 2 \mathrm{~T} 2}$. The role of RH in atmospheric new particle formation has been studied sparsely. Hamed et al. (2011) concluded that the observed decreases in atmospheric new particle formation rate at higher RHs are mostly due to the reduced sulphuric acid formation under cloudy and high-RH conditions. Several laboratory studies have investigated the role of RH in particle formation (e.g. Berndt et al., 2010; Brus et al., 2011; Zollner et al., 2012). In these studies increasing RH has typically enhanced particle formation, but the RH experiments have been conducted without information of the prevailing concentrations of (contaminant) amines. Thus, a detailed comparison between these studies and our results cannot be made.

Our results give some indications of the atmospheric particle formation process, even if the amines mainly determining the particle formation rates in atmosphere were different than those studied here. The similarities between atmospheric particle formation rates and the modelled formation rates $J_{\mathrm{A} 2 \mathrm{~T} 2}$ and $J_{\mathrm{A} 2 \mathrm{D} 1 \mathrm{~T} 1}$ suggest that atmospheric particle formation from gas phase acids and bases occurs via exactly two cluster sizes for which evaporation is the main sink. Because the inverse proportionality between coefficients $K_{\mathrm{A} 2 \mathrm{~B} 2}$ related to TMA and RH arises eventually from the complete surrounding of the nitrogen atom in TMA by alkyl groups (thus leaving no room for hydrogen bonds with water), the observed decrease in particle formation rates with increasing $\mathrm{RH}$ suggest that atmospheric particle formation is related, if not particularly to TMA, then to some other tertiary amines.

The results of our study show that both evolvement of measurement techniques for determining the atmospheric amine concentrations and further quantum chemical calculations on the sulphuric acid-amine-clusters are necessary for determining the main pathways of the atmospheric particle formation. Elucidating the stabilities of clusters with other amines in the size range studied here would substantially increase our understanding of the distribution of atmospheric sulphuric acid clusters and their capability to grow. Furthermore, the stability of clusters consisting of TMA and more than two sulphuric acid molecules, as well as the possibility of some oxidized organic vapours to adhere to the $\mathrm{A}_{2} \mathrm{~B}_{2}$ clusters, are of much interest. From the experimental point of view, the effects of temperature and prevailing sulphuric acid concentration on the power of sulphuric acid concentration associated with the observed particle formation rates should be investigated in more detail, both within and between particle formation event days.

\section{Supplementary material related to this article is available online at: http://www.atmos-chem-phys.net/12/ 9113/2012/acp-12-9113-2012-supplement.pdf.}

Acknowledgements. This work was funded by European Research Council (27463-ATMNUCLE and 257360-MOCAPAF), Academy of Finland (project numbers 1127372, 139656 and 251007, Center of Excellence program project number 1118615, LASTU program project number 135054), Maj and Tor Nessling Foundation (project numbers 2010212 and 2011200) and US Department of Energy grant DE-SC0006861. We thank CSC-IT Center for Science in Espoo, Finland, for computing time, and Sanna-Liisa Sihto for providing the particle formation rate data related to QUEST II and IV campaigns.

Edited by: I. Riipinen

\section{References}

Berndt, T., Stratmann, F., Sipilä, M., Vanhanen, J., Petäjä, T., Mikkilä, J., Grüner, A., Spindler, G., Lee Mauldin III, R., Curtius, J., Kulmala, M., and Heintzenberg, J.: Laboratory study on new particle formation from the reaction $\mathrm{OH}+\mathrm{SO}_{2}$ : influence of experimental conditions, $\mathrm{H}_{2} \mathrm{O}$ vapour, $\mathrm{NH}_{3}$ and the amine tert-butylamine on the overall process, Atmos. Chem. Phys., 10, 7101-7116, doi:10.5194/acp-10-7101-2010, 2010.

Berresheim, H., Elste, T., Plass-Dülmer, C., Eisele, F. L., and Tanner, D. J.: Chemical ionization mass spectrometer for long-term measurements of atmospheric $\mathrm{OH}$ and $\mathrm{H}_{2} \mathrm{SO}_{4}$, Int. J. Mass Spectrom., 202, 91-109, 2000.

Brus, D., Neitola, K., Hyvärinen, A.-P., Petäjä, T., Vanhanen, J., Sipilä, M., Paasonen, P., Kulmala, M., and Lihavainen, H.: Homogenous nucleation of sulfuric acid and water at close to atmospherically relevant conditions, Atmos. Chem. Phys., 11, 52775287, doi:10.5194/acp-11-5277-2011, 2011.

Bzdek, B. R., Ridge, D. P., and Johnston, M. V.: Amine exchange into ammonium bisulfate and ammonium nitrate nuclei, Atmos. Chem. Phys., 10, 3495-3503, doi:10.5194/acp-10-3495-2010, 2010.

Bzdek, B. R., Ridge, D. P., and Johnston, M. V.: Amine reactivity with charged sulfuric acid clusters, Atmos. Chem. Phys., 11, 8735-8743, doi:10.5194/acp-11-8735-2011, 2011.

Chebbi, A. and Carlier, P.: Carboxylic Acids in the Troposphere, Occurrence, Sources and Sinks: a Review, Atmos. Environ., 30, 4233-4249, 1996.

Dal Maso, M., Sogacheva, L., Aalto, P. P., Riipinen, I., Komppula, M., Tunved, P., Korhonen, L., Suur-Uski, V., Hirsikko, A., Kurtén, T., Kerminen, V.-M., Lihavainen, H., Viisanen, Y., Hansson, H.-C., and Kulmala, M.: Aerosol size distribution measurements at four Nordic field stations: identification, analysis and trajectory analysis of new particle formation events, Tellus, 59B, 350-361, 2007.

DePalma, J. W., Bzdek, B. R., Doren, D. J., and Johnston, M. V.: Structure and energetics of nanometer size clusters of sulfuric acid with ammonia and dimethylamine, J. Phys. Chem. A, 116, 1030-1040, 2011. 
Ehn, M., Junninen, H., Schobesberger, S., Manninen, H. E., Franchin, A., Sipilä, M., Petäjä, T., Kerminen, V.-M., Tammet, H., Mirme, A., Mirme, S., Hõrrak, U., Kulmala, M., and Worsnop, D. R.: An instrumental comparison of mobility and mass measurements of atmospheric small ions, Aerosol Sci. Technol., 45, 522-532, 2011.

Erupe, M. E., Viggiano, A. A., and Lee, S.-H.: The effect of trimethylamine on atmospheric nucleation involving $\mathrm{H}_{2} \mathrm{SO}_{4}$, Atmos. Chem. Phys., 11, 4767-4775, doi:10.5194/acp-11-47672011, 2011.

Ge, X., Wexler, A. S. and Clegg, S. L.: Atmospheric amines - Part I. A review, Atmos. Environ., 45, 524-546, 2011.

Guenther, A., Hewitt, C. N., Erickson, D., Fall, R., Geron, C., Graedel, T., Harley, P., Klinger, L., Lerdau, M., Mckay, W. A., Pierce, T., Scholes, B., Steinbrecher, R., Tallamraju, R., Taylor, J., and Zimmermann, P.: A global model of natural volatile organic compound emissions, J. Geophys. Res., 100, 8873-8892, doi:10.1029/94JD02950, 1995.

Hamed, A., Korhonen, H., Sihto, S.-L., Joutsensaari, J., Järvinen, H., Petäjä, T., Arnold, F., Nieminen, T., Kulmala, M., Smith, J. N., Lehtinen., K. E. J., and Laaksonen, A:, The role of relative humidity in continental new particle formation, J. Geophys. Res., 116, D03202, doi:10.1029/2010JD014186, 2011.

Hanson, D. R., McMurry, P. H., Jiang, J., Tanner, D., and Huey, L. G.: Ambient Pressure Proton Transfer Mass Spectrometry: Detection of Amines and Ammonia, Environ. Sci. Technol., 45, 8881-8888, 2011.

Iida, K., Stolzenburg, M. R., McMurry, P. H., and Smith, J. N.: Estimating nanoparticle growth rates from sizedependent charged fractions: Analysis of new particle formation events in Mexico City, J. Geophys. Res., 113, D05207, doi:10.1029/2007JD009260, 2008.

Kazil, J., Stier, P., Zhang, K., Quaas, J., Kinne, S., O’Donnell, D., Rast, S., Esch, M., Ferrachat, S., Lohmann, U., and Feichter, J.: Aerosol nucleation and its role for clouds and Earth's radiative forcing in the aerosol-climate model ECHAM5-HAM, Atmos. Chem. Phys., 10, 10733-10752, doi:10.5194/acp-1010733-2010, 2010.

Kerminen, V.-M. and Kulmala, M.: Analytical formulae connecting the "real" and the "apparent" nucleation rate and the nuclei number concentration for atmospheric nucleation events, J. Aerosol Sci., 33, 609-622, 2002.

Kerminen, V.-M., Petäjä, T., Manninen, H. E., Paasonen, P., Nieminen, T., Sipilä, M., Junninen, H., Ehn, M., Gagné, S., Laakso, L., Riipinen, I., Vehkamäki, H., Kurtén, T., Ortega, I. K., Dal Maso, M., Brus, D., Hyvärinen, A., Lihavainen, H., Leppä, J., Lehtinen, K. E. J., Mirme, A., Mirme, S., Hõrrak, U., Berndt, T., Stratmann, F., Birmili, W., Wiedensohler, A., Metzger, A., Dommen, J., Baltensperger, U., Kiendler-Scharr, A., Mentel, T. F., Wildt, J., Winkler, P. M., Wagner, P. E., Petzold, A., Minikin, A., Plass-Dülmer, C., Pöschl, U., Laaksonen, A., and Kulmala, M.: Atmospheric nucleation: highlights of the EUCAARI project and future directions, Atmos. Chem. Phys., 10, 10829-10848, doi:10.5194/acp-10-10829-2010, 2010.

Kirkby, J., Curtius, J., Almeida, J., Dunne, E., Duplissy, J., Ehrhart, S., Franchin, A., Gagné, S., Ickes, L., Kürten, A., Kupc, A., Metzger, A., Riccobono, F., Rondo, L., Schobesberger, S., Tsagkogeorgas, G., Wimmer, D., Amorim, A., Bianchi, F., Breitenlechner, M., David, A., Dommen, J., Downard, A., Ehn, M., Flagan,
R.C., Haider, S., Hansel, A., Hauser, D., Jud, W., Junninen, H., Kreissl, F., Kvashin, A., Laaksonen, A., Lehtipalo, K., Lima, J., Lovejoy, E.R., Makhutov, V., Mathot, S., Mikkilä, J., Minginette, P., Mogo, S., Nieminen, T., Onnela, A., Pereira, A., Petäjä, T., Schnitzhofer, R., Seinfeld, J.H., Sipilä, M., Stozhkov, Y., Stratmann, F., Tome, A., Vanhanen, J., Viisanen Y., Vrtala, A., Wagner, P.E., Walther, H., Weingartner, E., Wex, H., Winkler, P.M., Carslaw, K.S., Worsnop, D.R., Baltensperger, U., and Kulmala, M.: The role of sulfuric acid, ammonia and galactic cosmic rays in atmospheric aerosol nucleation, Nature, 476, 429-433, 2011.

Korhonen, H., Sihto, S.-L., Kerminen, V.-M., and Lehtinen, K. E. J.: Evaluation of the accuracy of analysis tools for atmospheric new particle formation, Atmos. Chem. Phys., 11, 3051-3066, doi:10.5194/acp-11-3051-2011, 2011.

Kuang, C., McMurry, P. H., McCormick, A. V., and Eisele, F. L.: Dependence of nucleation rates on sulfuric acid vapor concentration in diverse atmospheric locations, J. Geophys. Res., 113, D10209, doi:10.1029/2007JD009253, 2008.

Kulmala, M.: Dynamical atmospheric cluster model, Atmos. Res., 98, 201-206, 2010.

Kulmala, M. and Kerminen, V.-M.: On the formation and growth of atmospheric nanoparticles, Atmos. Res., 90, 132-150, 2008.

Kulmala, M., Vehkamäki, H., Petäjä, T., Dal Maso, M., Lauri, A., Kerminen, V.-M., Birmili, W., and McMurry, P. H.: Formation and growth rates of ultrafine atmospheric particles: A review of observations, J. Aerosol Sci., 35, 143-176, 2004.

Kulmala, M., Lehtinen, K. E. J., and Laaksonen, A.: Cluster activation theory as an explanation of the linear dependence between formation rate of $3 \mathrm{~nm}$ particles and sulphuric acid concentration, Atmos. Chem. Phys., 6, 787-793, doi:10.5194/acp-6-787-2006, 2006.

Kulmala, M., Riipinen, I., Sipilä, M., Manninen, H. E., Petäjä, T., Junninen, H., Dal Maso, M., Mordas, G., Mirme, A., Vana, M., Hirsikko, A., Laakso, L., Harrison, R. M., Hanson, I., Leung, C., Lehtinen, K. E. J., and Kerminen, V.-M.: Toward direct measurement of atmospheric nucleation, Science, 318, 89-92, 2007.

Kulmala, M., Asmi, A., Lappalainen, H. K., Baltensperger, U., Brenguier, J.-L., Facchini, M. C., Hansson, H.-C., Hov, Ø., O’Dowd, C. D., Pöschl, U., Wiedensohler, A., Boers, R., Boucher, O., de Leeuw, G., Denier van der Gon, H. A. C., Feichter, J., Krejci, R., Laj, P., Lihavainen, H., Lohmann, U., McFiggans, G., Mentel, T., Pilinis, C., Riipinen, I., Schulz, M., Stohl, A., Swietlicki, E., Vignati, E., Alves, C., Amann, M., Ammann, M., Arabas, S., Artaxo, P., Baars, H., Beddows, D. C. S., Bergström, R., Beukes, J. P., Bilde, M., Burkhart, J. F., Canonaco, F., Clegg, S. L., Coe, H., Crumeyrolle, S., D’Anna, B., Decesari, S., Gilardoni, S., Fischer, M., Fjaeraa, A. M., Fountoukis, C., George, C., Gomes, L., Halloran, P., Hamburger, T., Harrison, R. M., Herrmann, H., Hoffmann, T., Hoose, C., Hu, M., Hyvärinen, A., Hõrrak, U., Iinuma, Y., Iversen, T., Josipovic, M., Kanakidou, M., Kiendler-Scharr, A., Kirkevåg, A., Kiss, G., Klimont, Z., Kolmonen, P., Komppula, M., Kristjánsson, J.-E., Laakso, L., Laaksonen, A., Labonnote, L., Lanz, V. A., Lehtinen, K. E. J., Rizzo, L. V., Makkonen, R., Manninen, H. E., McMeeking, G., Merikanto, J., Minikin, A., Mirme, S., Morgan, W. T., Nemitz, E., O’Donnell, D., Panwar, T. S., Pawlowska, H., Petzold, A., Pienaar, J. J., Pio, C., Plass-Duelmer, C., Prévôt, A. S. H., Pryor, S., Reddington, C. L., Roberts, G., Rosenfeld, D., Schwarz, J., Seland, Ø., Sellegri, K., Shen, X. J., Shiraiwa, M., 
Siebert, H., Sierau, B., Simpson, D., Sun, J. Y., Topping, D., Tunved, P., Vaattovaara, P., Vakkari, V., Veefkind, J. P., Visschedijk, A., Vuollekoski, H., Vuolo, R., Wehner, B., Wildt, J., Woodward, S., Worsnop, D. R., van Zadelhoff, G.-J., Zardini, A. A., Zhang, K., van Zyl, P. G., Kerminen, V.-M., S Carslaw, K., and Pandis, S. N.: General overview: European Integrated project on Aerosol Cloud Climate and Air Quality interactions (EUCAARI) - integrating aerosol research from nano to global scales, Atmos. Chem. Phys., 11, 13061-13143, doi:10.5194/acp11-13061-2011, 2011.

Kulmala, M., Petäjä, T., Nieminen, T., Sipilä, M., Manninen, H. E., Lehtipalo, K., Dal Maso, M., Aalto, P. P., Junninen, H., Paasonen, P., Riipinen, I., Lehtinen, K. E. J., Laaksonen, A., and Kerminen, V.-M.: Measurement of the nucleation of atmospheric aerosol particles, Nature Protocols, 7, 1651-1667, 2012.

Kupiainen, O., Ortega, I. K., Kurtén, T., and Vehkamäki, H.: Amine substitution into sulfuric acid - ammonia clusters, Atmos. Chem. Phys., 12, 3591-3599, doi:10.5194/acp-12-3591-2012, 2012.

Kurtén, T., Noppel, M., Vehkamäki, H., Salonen, M., and Kulmala, M.: Quantum chemical studies of hydrate formation of $\mathrm{H}_{2} \mathrm{SO}_{4}$ and $\mathrm{HSO}_{4}^{-}$, Boreal Env. Res. 12, 431-453, 2007.

Kurtén, T., Loukonen, V., Vehkamäki, H., and Kulmala, M.: Amines are likely to enhance neutral and ion-induced sulfuric acid-water nucleation in the atmosphere more effectively than ammonia, Atmos. Chem. Phys., 8, 4095-4103, doi:10.5194/acp-8-4095-2008, 2008.

Kurtén, T., Petäjä, T., Smith, J., Ortega, I. K., Sipilä, M., Junninen, H., Ehn, M., Vehkamäki, H., Mauldin, L., Worsnop, D. R., and Kulmala, M.: The effect of $\mathrm{H}_{2} \mathrm{SO}_{4}$ - amine clustering on chemical ionization mass spectrometry (CIMS) measurements of gas-phase sulfuric acid, Atmos. Chem. Phys., 11, 3007-3019, doi:10.5194/acp-11-3007-2011, 2011.

Loukonen, V., Kurtén, T., Ortega, I. K., Vehkamäki, H., Pádua, A. A. H., Sellegri, K., and Kulmala, M.: Enhancing effect of dimethylamine in sulfuric acid nucleation in the presence of water - a computational study, Atmos. Chem. Phys., 10, 49614974, doi:10.5194/acp-10-4961-2010, 2010.

Makkonen, R., Asmi, A., Kerminen, V.-M., Boy, M., Arneth, A., Hari, P., and Kulmala, M.: Air pollution control and decreasing new particle formation lead to strong climate warming, Atmos. Chem. Phys., 12, 1515-1524, doi:10.5194/acp-12-15152012, 2012.

Manninen, H. E., Nieminen, T., Riipinen, I., Yli-Juuti, T., Gagné, S., Asmi, E., Aalto, P. P., Petäjä, T., Kerminen, V.-M., and Kulmala, M.: Charged and total particle formation and growth rates during EUCAARI 2007 campaign in Hyytiälä, Atmos. Chem. Phys., 9, 4077-4089, doi:10.5194/acp-9-4077-2009, 2009.

Mauldin, III, R., Tanner, D., Heath, J., Huebert, B., and Eisele, F.: Observations of $\mathrm{H} 2 \mathrm{SO} 4$ and MSA during PEM-Tropics-A, J. Geophys. Res., 104, 5801-5816, 1999.

McMurry, P. H. and Eisele, F. L.: Preface to Topical Collection on Nucleation and Growth in Urban Atlanta, J. Geophys. Res., 110, D22S01, doi:2005006644, 2005.

McMurry, P. H. and Friedlander, S. K.: New particle formation in the presence of aerosol, Atmos. Environ., 13, 1635-1651, 1979.

Merikanto, J., Spracklen, D. V., Mann, G. W., Pickering, S. J., and Carslaw, K. S.: Impact of nucleation on global CCN, Atmos. Chem. Phys., 9, 8601-8616, doi:10.5194/acp-9-8601-2009, 2009.
Metzger, A., Verheggen, B., Dommen, J., Duplissy, J., Prevot, A. S., Weingartner, E., Riipinen, I., Kulmala, M., Spracklen, D. V., Carslaw, K. S., and Baltensperger, U.: Evidence for the role of organics in aerosol particle formation under atmospheric conditions, P. Natl. Acad. Sci., 107, 6646-6651, doi:10.1073/pnas.0911330107, 2010.

Mikkonen, S., Romakkaniemi, S., Smith, J. N., Korhonen, H., Petäjä, T., Plass-Duelmer, C., Boy, M., McMurry, P. H., Lehtinen, K. E. J., Joutsensaari, J., Hamed, A., Mauldin III, R. L., Birmili, W., Spindler, G., Arnold, F., Kulmala, M., and Laaksonen, A.: A statistical proxy for sulphuric acid concentration, Atmos. Chem. Phys., 11, 11319-11334, doi:10.5194/acp-11-11319-2011, 2011.

Mirme, S., Mirme, A., Minikin, A., Petzold, A., Hõrrak, U., Kerminen, V.-M., and Kulmala, M.: Atmospheric sub-3 nm particles at high altitudes, Atmos. Chem. Phys., 10, 437-451, doi:10.5194/acp-10-437-2010, 2010.

Murphy, S. M., Sorooshian, A., Kroll, J. H., Ng, N. L., Chhabra, P., Tong, C., Surratt, J. D., Knipping, E., Flagan, R. C., and Seinfeld, J. H.: Secondary aerosol formation from atmospheric reactions of aliphatic amines, Atmos. Chem. Phys., 7, 2313-2337, doi:10.5194/acp-7-2313-2007, 2007.

Nadykto, A. B., Yu, F., Jakovleva, M. V., Herb, J., and Xu, Y.: Amines in the Earth's Atmosphere: A Density Functional Theory Study of the Thermochemistry of Pre-Nucleation Clusters, Entropy., 13, 554-569, 2011.

Ortega, I. K., Kupiainen, O., Kurtén, T., Olenius, T., Wilkman, O., McGrath, M. J., Loukonen, V., and Vehkamäki, H.: From quantum chemical formation free energies to evaporation rates, Atmos. Chem. Phys., 12, 225-235, doi:10.5194/acp-12-225-2012, 2012.

Paasonen, P., Nieminen, T., Asmi, E., Manninen, H. E., Petäjä, T., Plass-Dülmer, C., Flentje, H., Birmili, W., Wiedensohler, A., Hõrrak, U., Metzger, A., Hamed, A., Laaksonen, A., Facchini, M. C., Kerminen, V.-M., and Kulmala, M.: On the roles of sulphuric acid and low-volatility organic vapours in the initial steps of atmospheric new particle formation, Atmos. Chem. Phys., 10, 11223-11242, doi:10.5194/acp-10-11223-2010, 2010.

Petäjä, T., Mauldin, III, R. L., Kosciuch, E., McGrath, J., Nieminen, T., Paasonen, P., Boy, M., Adamov, A., Kotiaho, T., and Kulmala, M.: Sulfuric acid and $\mathrm{OH}$ concentrations in a boreal forest site, Atmos. Chem. Phys., 9, 7435-7448, doi:10.5194/acp9-7435-2009, 2009.

Petäjä, T., Sipilä, M., Paasonen, P., Nieminen, T., Kurtén, T., Ortega, I. K., Stratmann, F., Vehkamäki, H., Berndt, T., and Kulmala, M.: Experimental observation of strongly bound dimers of sulphuric acid nucleating in the atmosphere, Phys. Rev. Lett., 106, 228302, 2011.

Pierce, J. R. and Adams, P. J.: Uncertainty in global CCN concentrations from uncertain aerosol nucleation and primary emission rates, Atmos. Chem. Phys., 9, 1339-1356, doi:10.5194/acp-91339-2009, 2009.

Riipinen, I., Sihto, S.-L., Kulmala, M., Arnold, F., Dal Maso, M., Birmili, W., Saarnio, K., Teinilä, K., Kerminen, V.-M., Laaksonen, A., and Lehtinen, K. E. J.: Connections between atmospheric sulphuric acid and new particle formation during QUEST III-IV campaigns in Heidelberg and Hyytiälä, Atmos. Chem. Phys., 7, 1899-1914, doi:10.5194/acp-7-1899-2007, 2007.

Riipinen, I., Pierce, J. R., Yli-Juuti, T., Nieminen, T., Häkkinen, S., Ehn, M., Junninen, H., Lehtipalo, K., Petäjä, T., Slowik, J., 
Chang, R., Shantz, N. C., Abbatt, J., Leaitch, W. R., Kerminen, V.-M., Worsnop, D. R., Pandis, S. N., Donahue, N. M., and Kulmala, M.: Organic condensation: a vital link connecting aerosol formation to cloud condensation nuclei $(\mathrm{CCN})$ concentrations, Atmos. Chem. Phys., 11, 3865-3878, doi:10.5194/acp-11-38652011, 2011.

Seinfeld, J. H. and Pandis, S. N.: Atmospheric Chemistry and Physics: From Air Pollution to Climate Change, John Wiley \& Sons, Inc., New York, 2006.

Shampine, L. F. and Reichelt, M. W.: The MATLAB ODE suite, SIAM J. Sci. Comput., 18, 1-22, 1997.

Sihto, S.-L., Kulmala, M., Kerminen, V.-M., Dal Maso, M., Petäjä, T., Riipinen, I., Korhonen, H., Arnold, F., Janson, R., Boy, M., Laaksonen, A., and Lehtinen, K. E. J.: Atmospheric sulphuric acid and aerosol formation: implications from atmospheric measurements for nucleation and early growth mechanisms, Atmos. Chem. Phys., 6, 4079-4091, doi:10.5194/acp-6-4079-2006, 2006.

Sipilä, M., Berndt, T., Petäjä, T., Brus, D., Vanhanen, J., Stramann, F., Patokoski, J., Mauldin III, R. L., Hyvärinen, A.P., Lihavainen, H., and Kulmala, M.: The role of sulfuric acid in atmospheric nucleation, Science, 327, 1243-1246, doi:10.1126/science.1180315, 2010.

Sjöstedt, S. J., Huey, L. G., Tanner, D. J., Peischl, J., Chen, G., Dibb, J. E., Lefer, B., Hutterli, M. A., Beyersdorf, A. J., Blake, N. J., Blake, D. R., Sueper, D., Ryerson, T., Burkhart, J., and Stohl, A.: Observations of hydroxyl and the sum of peroxy radicals at Summit, Greenland during summer 2003, Atmos. Environ., 41, 5122-5137, 2007.

Spracklen, D. V., Carslaw, K. S., Kulmala, M., Kerminen, V.-M., Mann, G. W., and Sihto, S.-L.: The contribution of boundary layer nucleation events to total particle concentrations on regional and global scales, Atmos. Chem. Phys., 6, 5631-5648, doi:10.5194/acp-6-5631-2006, 2006.

Spracklen, D. V., Carslaw, K. S., Kulmala, M., Kerminen, V.-M., Sihto, S.-L., Riipinen, I., Merikanto, J., Mann, G. W., Chipperfield, M. P., Wiedensohler, A., Birmili, W., and Lihavainen, H.: Contribution of particle formation to global cloud condensation nuclei concentrations, Geophys. Res. Lett., 35, L06808, doi:10.1029/2007GL033038, 2008.

Vehkamäki, H., McGrath, M. J., Kurtén, T., Julin, J., Lehtinen, K. E. J., and Kulmala, M.: Rethinking the application of the first nucleation theorem to particle formation, J. Chem. Phys., 136, 094107, doi:10.1063/1.3689227, 2012.
Wang, M. and Penner, J. E.: Aerosol indirect forcing in a global model with particle nucleation, Atmos. Chem. Phys., 9, 239-260, doi:10.5194/acp-9-239-2009, 2009.

Wang, Z. B., Hu, M., Yue, D. L., Zheng, J., Zhang, R. Y., Wiedensohler, A., Wu, Z. J., Nieminen, T., and Boy, M.: Evaluation on the role of sulfuric acid in the mechanisms of new particle formation for Beijing case, Atmos. Chem. Phys., 11, 12663-12671, doi:10.5194/acp-11-12663-2011, 2011.

Weber, R. J., Marti, J. J., McMurry, P. H., Eisele, F. L., Tanner, D. $\mathrm{J}$, and Jefferson, A.: Measured atmospheric new particle formation rates: Implications for nucleation mechanisms, Chem. Eng. Commun., 151, 53-64, 1996.

Yu, F. and Luo, G.: Simulation of particle size distribution with a global aerosol model: contribution of nucleation to aerosol and CCN number concentrations, Atmos. Chem. Phys., 9, 76917710, doi:10.5194/acp-9-7691-2009, 2009.

Yu, F., Luo, G., Bates, T. S., Anderson, B., Clarke, A., Kapustin, V., Yantosca, R. M., Wang, Y., and Wu, S.: Spatial distributions of particle number concentrations in the global troposphere: Simulations, observations, and implications for nucleation mechanisms, J. Geophys. Res., 115, D17205, doi:10.1029/2009JD013473, 2010.

Yu, H., McGraw, R., and Lee, S. H.: Effects of amines on formation of sub-3 nm particles and their subsequent growth, Geophys. Rev. Lett., 39, L02807, doi:10.1029/2011GL050099, 2012.

Zhang, R., Khalizov, A., Wang, L, Hu, M., and Xu, W.: Nucleation and growth of nanoparticles in the atmosphere, Chem. Rev., 112, 1957-2011, doi:10.1021/cr2001756, 2012.

Zhao, J., Smith, J. N., Eisele, F. L., Chen, M., Kuang, C., and McMurry, P. H.: Observation of neutral sulfuric acid-amine containing clusters in laboratory and ambient measurements, Atmos. Chem. Phys., 11, 10823-10836, doi:10.5194/acp-1110823-2011, 2011.

Zheng, J., Hu, M., Zhang, R., Yue, D., Wang, Z., Guo, S., Li, X., Bohn, B., Shao, M., He, L., Huang, X., Wiedensohler, A., and Zhu, T.: Measurements of gaseous $\mathrm{H}_{2} \mathrm{SO}_{4}$ by AP-ID-CIMS during CAREBeijing 2008 Campaign, Atmos. Chem. Phys., 11, 7755-7765, doi:10.5194/acp-11-7755-2011, 2011.

Zollner, J. H., Glasoe, W. A., Panta, B., Carlson, K. K., McMurry, P. H., and Hanson, D. R.: Sulfuric acid nucleation: power dependencies, variation with relative humidity, and effect of bases, Atmos. Chem. Phys., 12, 4399-4411, doi:10.5194/acp-12-43992012, 2012. 